\title{
Quantifying organic matter and functional groups in particulate matter filter samples from the southeastern United States - Part 1: Methods
}

\author{
Alexandra J. Boris ${ }^{1}$, Satoshi Takahama ${ }^{2}$, Andrew T. Weakley ${ }^{1}$, Bruno M. Debus ${ }^{1}$, Carley D. Fredrickson ${ }^{1, a}$, \\ Martin Esparza-Sanchez ${ }^{1}$, Charlotte Burki ${ }^{2}$, Matteo Reggente ${ }^{2}$, Stephanie L. Shaw ${ }^{3}$, Eric S. Edgerton ${ }^{4}$, and \\ Ann M. Dillner ${ }^{1}$ \\ ${ }^{1}$ Air Quality Research Center, University of California Davis, Davis, CA 95616, USA \\ ${ }^{2}$ ENAC/IIE Swiss Federal Institute of Technology Lausanne (EFPL), Lausanne, Switzerland \\ ${ }^{3}$ Electric Power Research Institute, Palo Alto, CA 94304, USA \\ ${ }^{4}$ Atmospheric Research \& Analysis, Inc., Cary, NC 27513, USA \\ a now at: Department of Atmospheric Sciences, University of Washington, Seattle, WA 89195, USA
}

Correspondence: Ann M. Dillner (amdillner@ucdavis.edu)

Received: 9 April 2019 - Discussion started: 14 May 2019

Revised: 7 August 2019 - Accepted: 8 August 2019 - Published: 10 October 2019

\begin{abstract}
Comprehensive techniques to describe the organic composition of atmospheric aerosol are needed to elucidate pollution sources, gain insights into atmospheric chemistry, and evaluate changes in air quality. Fourier transform infrared absorption (FT-IR) spectrometry can be used to characterize atmospheric organic matter (OM) and its composition via functional groups of aerosol filter samples in air monitoring networks and research campaigns. We have built FT-IR spectrometry functional group calibration models that improve upon previous work, as demonstrated by the comparison of current model results with those of previous models and other OM analysis methods. Laboratory standards that simulated the breadth of the absorbing functional groups in atmospheric OM were made: particles of relevant chemicals were first generated, collected, and analyzed. Challenges of collecting atmospherically relevant particles and spectra were addressed by including interferences of particle water and other inorganic aerosol constituents and exploring the spectral effects of intermolecular interactions. Calibration models of functional groups were then constructed using partial least-squares (PLS) regression and the collected laboratory standard data. These models were used to quantify concentrations of five organic functional groups and OM in 8 years of ambient aerosol samples from the southeastern aerosol research and characterization (SEARCH) network. The results agreed with values estimated using other
\end{abstract}

methods, including thermal optical reflectance (TOR) organic carbon $\left(\mathrm{OC} ; R^{2}=0.74\right)$ and $\mathrm{OM}$ calculated as a difference between total aerosol mass and inorganic species concentrations $\left(R^{2}=0.82\right)$. Comparisons with previous calibration models of the same type demonstrate that this new, more complete suite of chemicals has improved our ability to estimate oxygenated functional group and overall OM concentrations. Calculated characteristic and elemental ratios including $\mathrm{OM} / \mathrm{OC}, \mathrm{O} / \mathrm{C}$, and $\mathrm{H} / \mathrm{C}$ agree with those from previous work in the southeastern US, substantiating the aerosol composition described by FT-IR calibration. The median $\mathrm{OM} / \mathrm{OC}$ ratio over all sites and years was $2.1 \pm 0.2$. Further results discussing temporal and spatial trends of functional group composition within the SEARCH network will be published in a forthcoming article.

\section{Introduction}

\subsection{Challenges of quantifying atmospheric aerosol organic matter mass}

Atmospheric aerosol organic matter (OM) composition, sources, and formation processes have been a focus of research for many decades (Haagen-Smit, 1952; Went, 1960). 
However, because the organic fraction of aerosol particles contains thousands of individual chemical compounds (Schum et al., 2018a), it is a difficult task to characterize the total OM composition of an aerosol sample. Typical molecular-level analytical techniques quantify up to $30 \%$ of OM concentration (Hallar et al., 2013). Chromatography techniques suffer from needing to have sufficient molecular selectivity and sensitivity for each chemical, requiring calibration of each species. As an alternative, rather than quantifying each chemical, the total OM concentration can be measured.

Some analytical techniques such as aerosol mass spectrometry can quantify OM concentrations in real time (Aiken et al., 2008). Other methods with involved chemical analyses of discrete filter samples have been used to estimate $\mathrm{OM}$ concentration. These include multiple linear regression of aerosol constituents using various analytical techniques (Hand et al., 2019; Malm and Hand, 2007; Simon et al., 2011), extrapolation from gas chromatography-mass spectrometry of extracts (Turpin and Lim, 2001), infrared absorption spectrometry of extracts (Polidori et al., 2008), or thermal-optical and gravimetric analyses of extracts (ElZanan et al., 2009). However, each of these methods is subject to specific limitations. Aerosol mass spectrometry OM concentrations, for example, are subject to uncertainties resulting from fragmentation and high heat exposure (Canagaratna et al., 2015). Filter extraction procedures can result in the loss of organic species (Kawamura and Bikkina, 2016) and render a sample unusable for further analysis, while multiple linear regression and mass balance techniques require accurate estimation of all inorganic species concentrations, which can involve large uncertainties (e.g., ignoring particle water mass or losses of volatile ammonium and nitrate during $\mathrm{NH}_{4} \mathrm{NO}_{3}$ collection from different filter media; Chow et al., 2015; Yu et al., 2006).

The methods of estimating OM concentrations listed above are either not feasible or have substantial uncertainty for measurements that are remote, resource-limited, or longterm (e.g., multi-year). Analyses of OM for routine monitoring networks have specific requirements. Because of the large number of samples, collection must be simple, and the cost of analysis must be low. Nondestructive, filter-based techniques are also desirable for networks because they allow for multiple chemical analyses to be performed on one sample.

In air monitoring networks, OM concentrations are typically estimated indirectly from organic carbon (OC) concentrations (Edgerton et al., 2005; Pitchford et al., 2007). While $\mathrm{OM}$ includes other atoms such as $\mathrm{O}$ and $\mathrm{H}$ associated with $\mathrm{C}$ (sometimes also N, S, and P; Russell, 2003), OC accounts for only the $\mathrm{C}$ atoms. Sample OM concentration is typically determined from thermal optical reflectance (TOR) OC by multiplying the $\mathrm{OC}$ concentration by a static ratio of OM/OC. An OM/OC value of 1.4 for urban samples (White et al., 1977) or 1.8 for rural samples (Pitchford et al., 2007) is typ- ically used, although a value 2.1 for rural areas (Turpin and Lim, 2001) has been broadly cited. However, OM/OC varies widely amongst ambient samples. For example, Ruthenburg et al. (2014) estimated values varying between 1.46 and 2.01 (10th and 90th percentiles) in 1 year of samples at seven rural US locations. This and other observed OM/OC variability suggests that a static value of $\mathrm{OM} / \mathrm{OC}$ is not adequate to capture the spatial and temporal variations in OM. A technique for routine $\mathrm{OM}$ concentration measurement in ambient aerosol at network sites is therefore needed.

\subsection{Using infrared absorption of functional groups to quantify aerosol OM}

Fourier transform infrared absorption (FT-IR) spectrometry can be used to quantify most of the organic aerosol concentration in a given sample by functional groups (Coury and Dillner, 2009; Faber et al., 2017; George et al., 2015; Reff et al., 2005; Russell et al., 2011; Ruthenburg et al., 2014). Measuring functional group concentrations in ambient aerosol samples is useful to (1) accurately estimate the total OM concentration, (2) further characterize the OM composition by functional groups, (3) monitor organic composition and sources of aerosol over time, and (4) estimate the degree of oxidation. The FT-IR spectrometry approach is particularly useful for routine and network OM measurements because it can be applied to filter samples that are routinely collected for other purposes (e.g., particulate matter mass), is nondestructive, and is inexpensive.

The principle of organic characterization through FT-IR spectrometry is as follows: chemical bonds with appropriate vibrational symmetries and frequencies absorb light at specific mid-infrared wavelength ranges, allowing the determination of the bond type and, in some cases, even molecular environment. The magnitude of the light absorption is proportional to the number of bonds present, allowing the direct quantification of bonds within an aerosol sample (Allen et al., 1994).

Infrared absorption spectrometry has been used to quantify functional groups using a peak-fitting approach (Takahama et al., 2013), but factor-based calibration of spectra can more readily determine interferents and is strengthened by using multiple spectral bands at once (Naes et al., 2002). Specifically, partial least-squares (PLS) regression has been used in factor-based work. A comparison of the peak fitting and PLS calibration methods has been recently discussed (Reggente et al., 2019). In a PLS functional group calibration, concentrations of pure chemical standards are regressed onto their corresponding FT-IR spectra to reduce the number of variables describing the data. These new variables, sometimes called "factors", are identified to explain the covariance between the chemical standard concentrations and spectra. Each functional group is quantified (typically by mole) as a weighted sum of the extracted factors, resulting in a unique calibration model for each functional group (see Sect. 2.5, Supple- 
ment Sect. S10, and Naes et al., 2002). Examples of PLS calibration of functional groups in atmospheric OM include the work of Reff et al. (2007), Coury and Dillner (2009), Ruthenburg et al. (2014), and Kamruzzaman et al. (2018).

Calibration curves are developed from "laboratory standards": pure chemicals collected onto fresh polytetrafluoroethylene (PTFE) filters. The chemical mass collected is varied to capture the relationship between infrared absorption and number of bonds (Coury and Dillner, 2008). Ruthenburg et al. (2014) built a set of FT-IR-PLS calibration models using nine organic chemicals and one inorganic salt interferent (ammonium sulfate) to quantify four functional groups: aliphatic $\mathrm{C}-\mathrm{H}$, carbonyl $(\mathrm{C}=\mathrm{O})$, carboxylic acid $\mathrm{O}-\mathrm{H}$, and alcoholic $\mathrm{O}-\mathrm{H}$. The concentrations of these functional groups (and OM concentrations as weighted sums of these functional groups) were predicted in ambient filter samples collected from seven IMPROVE network sites in 2011. The same measurements were made, adding an amine functional group model, for a larger group of IMPROVE network sites from 2013 (Kamruzzaman et al., 2018). However, the relatively short list of chemicals to represent atmospheric composition likely limited the ability of these models to characterize the aerosol composition fully. Previous work was also done with a more comprehensive list of chemical standards; unfortunately, the particular measurement technique damaged the filter samples, which is not desirable for air monitoring network data (Coury and Dillner, 2008).

\subsection{Functional group calibration method improvements}

Efforts to improve FT-IR functional group concentration measurements involve addressing the following challenges: (1) approximating atmospheric composition by selecting appropriate lists of chemicals and functional groups for calibration, (2) considering ambient aerosol molecular environments, including particle water content, (3) selecting appropriate model parameters based on the current understanding of atmospheric composition, (4) validating models when methods for direct comparison are lacking, and (5) quantifying as much of the OM mass as possible given that most, but not all, relevant molecular bonds absorb in the mid-infrared spectral range. The following paragraphs discuss these challenges in more detail.

The selection of chemicals is nontrivial: atmospherically representative bonds must be selected to enable the calibration to capture the variation in ambient samples. It is not possible to generate standards of the thousands of individual molecules that exist within aerosol samples, many of which have not yet been identified (Schum et al., 2018). An appropriate starting point for the list of chemical standards used in the calibration models is the atmospheric speciation reported in previous studies. The molecular bonds (or functional groups) included in the calibration must represent the majority of the OM. In addition, efforts to measure subgroups of functional groups within a broad functional group category such as carbonyl groups are made (e.g., inclusion of dicarboxylic acids and amino acids), while recognizing the limitations of subdividing groups given overlapping spectral features. In addition, inorganic species that absorb infrared light must be included as "interferents" in a robust calibration model.

Laboratory standards are prepared with the goal of capturing the molecular structures and intermolecular interactions most relevant for the atmosphere. The infrared spectrum of a molecule is affected by its chemical environment, including its hydrogen and ionic bonding interactions with other molecules in a sample (Davey et al., 2006; Mayo et al., 2003). Ideally, the variety of interactions between the many molecules in ambient aerosol particles would be modeled by the calibration to capture the variability in infrared spectral features. The bonding structures within particles of single, pure chemicals, and between mixtures of chemicals, may also warrant consideration. Mixtures can probe for interactions between different types of polar organic functional groups (hydrogen bonding), as well as organic with inorganic ions (ionic bonding, such as carboxylates). Water that is chemically or physically bound to collected ambient aerosol particles is also expected to alter ambient samples spectroscopically and could be abundant (Dabek-Zlotorzynska et al., 2011). The presence of water could induce molecular transitions, such as formation of gem-diols from carbonyls (Maron et al., 2011), or enhance spectral features of particle water: as liquid water associated with particles (Faber et al., 2017) or as hydrate water chemically bound to particle chemical constituents (Cziczo and Abbatt, 2000). Laboratory-generated particles under humid conditions may display these spectral impacts of water, and may be useful as inputs to inform models.

The inputs to PLS models must be carefully selected to minimize measurement uncertainty. Examples of inputs include the concentration range of the chemical standards and the number of PLS factors included in each model. These inputs are selected based on the best available information but may need to be updated over time as understanding of atmospheric composition improves.

Few methods exist for verifying FT-IR spectrometry functional group concentrations. Strong correlations have been found between ratios of FT-IR spectrometry measurements with high-resolution aerosol mass spectrometry tracer ions (e.g., ratioed carboxylic acids and $\mathrm{C}-\mathrm{H}$ groupings); direct (not ratioed) correlations between measurements were less successful (Faber et al., 2017; Russell et al., 2009a). Ruthenburg et al. (2014) quantitatively evaluated their FT-IR functional group concentrations by comparing $\mathrm{OC}$ concentrations from summed functional groups with TOR OC concentrations.

Although comprehensive in that a broad range of molecules in OM are detected, there are some limitations to the sensitivity of FT-IR spectrometry. Some bonds, such as 
tertiary C-C bonds and C-O bonds, do not absorb in midinfrared spectral regions or absorb where the filter substrate, PTFE, also absorbs (Weakley et al., 2016). Ongoing work using empirically based simulations aims to quantify this "mass recovery" of FT-IR-spectrometry-resolvable ambient OM (Burki et al., 2019).

\subsection{Summary of study goals}

The goal of this work is to further develop a method to measure functional group concentrations and calculate OM concentrations in ambient aerosol samples using FT-IR spectrometry and PLS calibration. Samples were collected by the SouthEastern Aerosol Research and Characterization (SEARCH; Hansen et al., 2003) network. There are two main components of achieving the overall study goal. The first is to expand upon previous work (Ruthenburg et al., 2014) to better characterize OM and address other challenges of FT-IR spectrometry and PLS calibration (as described in Sect. 1.3). The second is to evaluate the improved method by quantifying atmospheric functional group concentrations over multiple years at consistent locations.

To address the first component of achieving the study goal, a broader list of atmospherically relevant chemical standards were incorporated, including chemicals specific to the southeastern US. The functional groups included more specific subgroups than in previous work: aliphatic C-H groups, carboxylic acids, oxalates, non-oxalate and nonacid carbonyls, and alcohols. Additional interfering species, including particle water and ammonium nitrate, were accounted for, and molecular interactions expected in ambient samples were considered. Model parameters such as the number of regression factors were selected based in part on current atmospheric composition literature and focused studies using simulation methods.

To address the second component, SEARCH samples from 2009 to 2016 at five sampling sites with varying (urban or rural) emissions were analyzed. The calibration of SEARCH samples was particularly challenging due to interference from the thicker filter material and lower aerial density of particles than the IMPROVE samples used by Ruthenburg et al. (2014). The final models were evaluated qualitatively and semiquantitatively by comparing the ambient SEARCH functional group measurements with atmospheric composition measurements made using multiple analytical methods. For example, resulting OM and OC concentrations were compared with residual OM and TOR OC concentrations, respectively.

\section{Methods}

Ambient aerosol samples, collected onto Teflon filters from five SEARCH network sites over 8 years, were analyzed by FT-IR absorption spectrometry (Sect. 2.1). A series of lab- oratory standards that mimicked the ambient samples were collected using a range of relevant pure chemicals, and spectra were explored to confirm that molecular environments were atmospherically relevant (Sect. 2.2). After FT-IR spectra were acquired (Sect. 2.3), outliers were detected and were either set aside during model development or removed from the dataset (Sect. 2.4). Calibration models were developed to measure five functional groups using multivariate analysis (Sect. 2.5). The resulting calibration models were described by interpreting important spectral variables (Sect. 2.5.2). While no direct measurements for evaluating the functional group model measurements exist, estimates of OM concentrations from mass and measured components and TOR OC concentrations were used for comparison, and the van Krevelen space was used to compare other measurements of aerosol composition (Sect. 2.5.2). Method detection limits were applied (Sect. 2.5.3), and uncertainties in model measurements of functional groups and predictions of OM quantities were estimated (Sect. 2.6).

\subsection{SEARCH network samples, network data, and field blanks}

Aerosol composition in the southeast was characterized from 1999 to 2016 by the SEARCH network. The SEARCH network was unique in that it focused on one region of the US, with sites in urban and rural pairs (Birmingham and Centreville in Alabama and Atlanta and Yorkville in Georgia). Measurement methods were advanced and comprehensive, including real-time gas-phase measurements, light and massbased measurements of total particles, a variety of particlephase composition measurements (trace elements, inorganic salts, OC, and elemental carbon), and supporting meteorological variables.

Filter samples of ambient aerosol collected in the SEARCH network from 2009-2016 were used in the present study. The sampling sites included urban Birmingham (BHM) and rural Centreville (CTR) in Alabama, urban Jefferson Street, Atlanta (JST), rural Yorkville (YRK) in Georgia, and a rural outlying landing field (OLF) near Pensacola in Florida (Edgerton et al., 2005). Samples from colocated samplers at the JST site (cJST) were used to calculate the sampling uncertainty of the functional group measurements (Sect. 2.6). Three additional SEARCH network sites were closed before 2016 and were therefore not included in the current study; sampling in the SEARCH network ended in 2016, on different dates for each site.

Samples analyzed in this work were collected using the Federal Reference Method (U.S. Environmental Protection Agency, 2011). Briefly, Partisol Plus 2025 samplers (Rupprecht \& Patashnick, Fisher Scientific, http:// www.thermofisher.com/, last access: 9 December 2019) were used to collect ambient particulate matter smaller than $2.5 \mu \mathrm{m}$ aerodynamic diameter $\left(\mathrm{PM}_{2.5}\right)$ at $16.7 \mathrm{~L} \mathrm{~min}^{-1}$ onto MTL $47 \mathrm{~mm}$ PTFE filters with $2 \mu \mathrm{m}$ pore size (Measurement Tech- 
nology Laboratories, https://mtlcorp.com/filters, last access: 9 December 2019). Gravimetric analysis of $\mathrm{PM}_{2.5}$ mass and $\mathrm{X}$-ray fluorescence of trace metals concentrations were performed using these filters. Additional filter samples were collected and analyzed by the SEARCH network (Edgerton et al., 2005). Quartz filters (37 mm) were used for TOR analysis of OC and elemental carbon concentrations. PTFE filters $(47 \mathrm{~mm})$ were used for $\mathrm{SO}_{4}^{2-}, \mathrm{NO}_{3}^{-}$, and $\mathrm{NH}_{4}^{+}$analyses. $\mathrm{Ny}-$ lon and cellulose filters $(47 \mathrm{~mm})$ were used for negative artifact $\mathrm{NO}_{3}^{-}$and $\mathrm{NH}_{4}^{+}$analyses, respectively. SEARCH TOR OC measurements are blank-corrected using annual networkwide mean field blank OC concentrations.

One-in-three-days, seasonally representative (January, April, July, and October) samples from 2009 to 2015, as well as daily samples from 2016, were analyzed using FTIR spectrometry. The one-in-three-days sampling schedule matched the sampling for TOR OC measurements. At each site, 30-45 samples were analyzed by FT-IR spectrometry per year from 2009 to 2015; 1474 ambient sample filters were included altogether in this study. A total of 359 field blank filters were used (approximately two field blank filters per month, per site).

In contrast to other networks, there were some advantages and challenges of SEARCH sampling for FT-IR analyses. Unlike IMPROVE samples, filters were shipped and stored at $<4{ }^{\circ} \mathrm{C}$ (from Aerosol Research and Analysis, Inc., ARA, in Morrisville, NC) to minimize loss of volatile species. Gravimetric filter measurements were made in an environmentally controlled weigh space to minimize uncertainty in water content (Edgerton et al., 2005), a control technique the IMPROVE network has only recently implemented. However, the mass loading of SEARCH network filter samples was generally lower than that of the IMPROVE network. While the IMPROVE network uses $25 \mathrm{~mm}$ diameter filters and a flow rate of $22.8 \mathrm{~L} \mathrm{~min}^{-1}$, the SEARCH network used relatively large filters $(47 \mathrm{~mm}$ diameter) and a lower flow rate $\left(16.7 \mathrm{~L} \mathrm{~min}^{-1}\right)$, following the Federal Reference Method (FRM) sampling procedures (Mikhailov et al., 2009). The Chemical Speciation Network (CSN) also uses $47 \mathrm{~mm}$ diameter filters for collection, and, similarly to SEARCH, filters are shipped and stored cold; however, the SEARCH aerosol loading was higher than that in the CSN, which uses a flow rate of $6.7 \mathrm{~L} \mathrm{~min}^{-1}$ and $47 \mathrm{~mm}$ diameter filters. In addition, the SEARCH filters were constructed of thicker PTFE material, overlapping some aerosol sample peaks in transmission spectrometry and producing strong, variable FT-IR spectral features related to scattering by PTFE.

\subsection{Laboratory standard generation}

Laboratory standards used to measure functional group concentrations were produced by collecting particles of pure chemicals onto $47 \mathrm{~mm}$ MTL PTFE filters to mimic ambient SEARCH network samples. The aerosol generation system consisted of an atomizer (model 3076 Constant Output At- omizer, TSI Inc.), a custom-built diffusion dryer, and a Partisol (FRM) aerosol sampler operated at $16.7 \mathrm{~L} \mathrm{~min}^{-1}$. The atomizer was supplied with pure chemical solutions and filtered house air (Model 3074B Filtered Air Supply, TSI Inc., http://www.TSI.com/, last access: 9 December 2019).

Two types of laboratory blanks were collected. "Chamber blanks" were collected using deionized (DI) water $(\geq$ 18.2 M $\Omega$ purity) for 10-180 min or isopropanol (IPA; Spectrum Spectrasolv grade) for 5-35 min. "Method blanks" were placed in the aerosol generation system and handled identically to laboratory standards, but the pump was not turned on. One method blank was collected while each pure chemical was being collected. Multiple pure chemicals (Table 1) were chosen to represent each of the organic functional groups calibrated (see Sect. 2.5).

For each pure chemical, 10-20 filters of varying masses were collected (for 1-35 min); 315 chemical standards were produced. The mass of functional group deposited onto each laboratory standard filter was calculated as the difference in filter mass (in $\mu \mathrm{g}$ ) before and after collection. Each filter was pre- and post-weighed at least three times using a high-precision balance $( \pm 2 \mu \mathrm{g}$; model XP2U, MettlerToledo, https://www.mt.com, last access: 9 December 2019). The total quantity of functional group anticipated in ambient samples, based on literature values, was used to determine the range collected for each chemical. For example, suberic acid standards were generated in the range of 0.04$4 \mu \mathrm{mol} \mathrm{C}=\mathrm{O}$ per filter, which is higher than expected for suberic acid itself (Gao et al., 2006) but within the range anticipated for total $\mathrm{C}=\mathrm{O}$ (Polidori et al., 2008). The range of measured functional group concentrations in ambient samples was also compared to the dynamic range included in the models (Sect. 3.3.2).

Most of the pure chemical solutions were prepared in IPA and/or DI water; a small number were prepared in ethanol (Koptec Pure Grade). Impurities in the solvents were identified by looking at FT-IR spectra of chamber blanks. However, weights of the impurities in the IPA and ethanol were within the uncertainty of the high-precision balance when collected for up to $35 \mathrm{~min}$, and were not predictive in the functional group models. No impurities were discovered in the DI water. Sonication for up to $2 \mathrm{~h}$ was used for some solutions. Concentrations and other details of the pure chemical solutions are listed in Sects. S1-S3.

Molecular environments of the laboratory standards were influential on the infrared spectra and were explored qualitatively (observations summarized in Sect. 3.2, and more detail compiled in Supplement). Hydrogen and ionic bonding patterns were interpreted within spectra of collected standards containing single chemicals. In some cases, a chemical was not included in the model due to a variable hydrogen bonding pattern. The influence of humidity on the laboratory standards was assessed by exposing a selection of laboratory standards to a dry and a wet environment (a desiccator with silica beads and a desiccator with water, respectively). Blank 
Table 1. Pure chemicals collected as laboratory standards and used in the calibration of FT-IR spectra for functional group concentrations.

\begin{tabular}{|c|c|c|c|c|c|c|c|}
\hline Pure chemical & $\begin{array}{l}\text { Chemical } \\
\text { character }\end{array}$ & Reason for inclusion in model & $\mathrm{O} / \mathrm{C}$ & $\mathrm{H} / \mathrm{C}$ & $\mathrm{OM} / \mathrm{OC}$ & Molecular structure & $\begin{array}{l}\text { Molecular } \\
\text { formula }\end{array}$ \\
\hline Squalene & $\begin{array}{l}\text { Unsaturated } \\
\text { hydrocarbon }\end{array}$ & Represents unsaturated hydrocarbons & 0.00 & 1.67 & 1.14 & & $\mathrm{C}_{30} \mathrm{H}_{50}$ \\
\hline Oxalic acid & Oxalic acid & $\begin{array}{l}\text { Abundant chemical in atmospheric } \\
\text { aerosol }\end{array}$ & 2.00 & 1.00 & 3.75 & & $\mathrm{C}_{2} \mathrm{H}_{2} \mathrm{O}_{4}$ \\
\hline Malonic acid & $\begin{array}{l}\text { Short chain } \\
\text { di-acid length }\end{array}$ & Abundant chemical in atmospheric aerosol & 1.33 & 1.33 & 2.89 & & $\mathrm{C}_{3} \mathrm{H}_{4} \mathrm{O}_{4}$ \\
\hline Succinic acid & $\begin{array}{l}\text { Short chain } \\
\text { length di-acid }\end{array}$ & Midrange length carboxylic acid & 1.00 & 1.50 & 2.67 & & $\mathrm{C}_{4} \mathrm{H}_{6} \mathrm{O}_{4}$ \\
\hline Suberic acid & $\begin{array}{l}\text { Medium chain } \\
\text { di-acid length }\end{array}$ & $\begin{array}{l}\text { Midrange to long carboxylic acid (spectrum } \\
\text { similar to long-chain mono-carboxylic acids) }\end{array}$ & 0.50 & 1.75 & 1.81 & & $\mathrm{C}_{8} \mathrm{H}_{14} \mathrm{O}_{4}$ \\
\hline Terephthalic acid & Aromatic acid & $\begin{array}{l}\text { Represents aromatic acids, especially } \\
\text { industrial emissions }\end{array}$ & 0.50 & 0.75 & 3.67 & & $\mathrm{C}_{8} \mathrm{H}_{6} \mathrm{O}_{4}$ \\
\hline D-alanine & Amino acid & $\begin{array}{l}\text { Amino acid abundant in atmospheric } \\
\text { aerosol }\end{array}$ & 0.67 & 2.33 & 2.47 & & $\mathrm{C}_{3} \mathrm{H}_{7} \mathrm{NO}_{2}$ \\
\hline Ammonium oxalate & Carboxylate salt & $\begin{array}{l}\text { Theoretically atmospherically abundant } \\
\text { carboxylate salt }\end{array}$ & 2.00 & 4.00 & 5.17 & & $\mathrm{C}_{2} \mathrm{H}_{8} \mathrm{~N}_{2} \mathrm{O}_{4}$ \\
\hline Sodium oxalate & Carboxylate salt & $\begin{array}{l}\text { Theoretically atmospherically abundant } \\
\text { carboxylate salt }\end{array}$ & 2.00 & 2.00 & 5.58 & & $\mathrm{C}_{2} \mathrm{O}_{4} \mathrm{Na}_{2}$ \\
\hline $\begin{array}{l}\text { D-(+)-glucono- } \\
\text { delta-Lactone }\end{array}$ & lactone & $\begin{array}{l}\text { Represents cyclic carbonyls, including } \\
\text { carbohydrates }\end{array}$ & 1.00 & 1.67 & 2.47 & & $\mathrm{C}_{6} \mathrm{H}_{10} \mathrm{O}_{6}$ \\
\hline Tannic "acid" & $\begin{array}{l}\text { Humic-like } \\
\text { substance }\end{array}$ & $\begin{array}{l}\text { Representative of oligomeric } \\
\text { substances (carbonyl, phenolic } \mathrm{OH} \text { ) }\end{array}$ & 0.61 & 0.68 & 1.86 & & $\mathrm{C}_{76} \mathrm{H}_{52} \mathrm{O}_{46}$ \\
\hline Ethyl palmitate & Aliphatic ester & Representative of esters & 0.11 & 2.00 & 1.32 & & $\mathrm{C}_{18} \mathrm{H}_{36} \mathrm{O}_{2}$ \\
\hline $\begin{array}{l}\text { 10-Nonadecanone } \\
\text { meso-Erythritol }\end{array}$ & $\begin{array}{l}\text { Aliphatic ketone } \\
\text { Biogenic tetrol }\end{array}$ & $\begin{array}{l}\text { Representative of ketones } \\
\text { Abundant product of isoprene oxidation }\end{array}$ & $\begin{array}{l}0.05 \\
1.00\end{array}$ & $\begin{array}{l}2.00 \\
2.50\end{array}$ & $\begin{array}{l}1.30 \\
2.54\end{array}$ & & $\begin{array}{l}\mathrm{C}_{19} \mathrm{H}_{38} \mathrm{O} \\
\mathrm{C}_{4} \mathrm{H}_{10} \mathrm{O}_{4}\end{array}$ \\
\hline D-(+)-glucose & Carbohydrate & Representative of carbohydrates & 1.00 & 2.00 & 2.50 & & $\mathrm{C}_{6} \mathrm{H}_{12} \mathrm{O}_{6}$ \\
\hline Levoglucosan & $\begin{array}{l}\text { Biomass burning } \\
\text { tracer }\end{array}$ & Tracer of biomass burning emissions & 0.83 & 1.67 & 2.25 & & $\mathrm{C}_{6} \mathrm{H}_{10} \mathrm{O}_{5}$ \\
\hline 4-Nitrocatechol & Phenol & $\begin{array}{l}\text { Representative of phenols, typical of } \\
\text { biomass burning emissions }\end{array}$ & 0.67 & 0.83 & 2.15 & & $\mathrm{C}_{6} \mathrm{H}_{5} \mathrm{NO}_{4}$ \\
\hline 1-Docosanol & $\begin{array}{l}\text { Long chain } \\
\text { length alcohol }\end{array}$ & Representative of fatty alcohols & 0.05 & 2.09 & 1.24 & & $\mathrm{C}_{22} \mathrm{H}_{46} \mathrm{O}$ \\
\hline
\end{tabular}


Table 1. Continued.

\begin{tabular}{|c|c|c|c|c|c|c|c|c|}
\hline Pure chemical & $\begin{array}{l}\text { Chemical } \\
\text { character }\end{array}$ & Reason for inclusion in model & $\mathrm{O} / \mathrm{C}$ & $\mathrm{H} / \mathrm{C}$ & $\mathrm{OM} / \mathrm{OC}$ & Molecular structure & & $\begin{array}{l}\text { Molecular } \\
\text { formula }\end{array}$ \\
\hline Ammonium sulfate & Interferent & $\begin{array}{l}\text { Abundant in atmospheric aerosol } \\
\text { (inorganic salt) }\end{array}$ & - & - & - & $\mathrm{NH}_{4}{ }^{+} \|_{\mathrm{O}}^{\mathrm{O}}-\mathrm{O}^{\circ}$ & $\mathrm{NH}_{4}{ }^{+}$ & $\left(\mathrm{NH}_{4}\right)_{2} \mathrm{SO}_{4}$ \\
\hline Ammonium nitrate & Interferent & $\begin{array}{l}\text { Abundant in atmospheric aerosol } \\
\text { (inorganic salt) }\end{array}$ & - & - & - & 임 & $\mathrm{NH}_{4}^{+}$ & $\mathrm{NH}_{4} \mathrm{NO}_{3}$ \\
\hline $\begin{array}{l}\text { Magnesium chloride, } \\
\text { hexahydrate }\end{array}$ & $\begin{array}{l}\text { Interferent } \\
\text { (water) }\end{array}$ & $\begin{array}{l}\text { Does not absorb in infrared region of interest but } \\
\text { is strongly hygroscopic so that the spectrum represents } \\
\text { particle (hydrate and liquid) water }\end{array}$ & - & - & - & $\mathrm{Cl}^{-} \mathrm{Mg}^{2+} \mathrm{Cl}^{-}$ & & $\mathrm{MgCl}_{2}$ \\
\hline
\end{tabular}

filters, as well as laboratory standard filters containing a hydrophobic chemical (squalene), were analyzed as controls. Each filter was exposed to each environment for 1 week.

\subsection{FT-IR spectrometry analysis: spectrum acquisition}

Analyses of the sample and laboratory standard filters were carried out in transmission mode on a Bruker Tensor II FT-IR spectrometer (Bruker Optics, Inc.; http://www.bruker.com/, last access: 9 December 2019) equipped with a mid-infrared light source and liquid nitrogen cooled mercury cadmium telluride detector. Each filter was placed into a custom-built (see Debus et al., 2019) chamber within the FT-IR spectrometer that was continuously flushed with air scrubbed of $\mathrm{H}_{2} \mathrm{O}$ and $\mathrm{CO}_{2}$ (model VCDA air purge system, Puregas, LLC, http://www.puregas.com/, last access: 9 December $2019 ;<10 \%$ humidity). Additional information about the FT-IR spectrometry analyses can be found elsewhere (Debus et al., 2018; Ruthenburg et al., 2014). Spectra were collected between 4000 and $420 \mathrm{~cm}^{-1}$, but 1500 to $400 \mathrm{~cm}^{-1}$ was excluded due to strong PTFE filter absorption (Weakley et al., 2016) and highly variable absorption between chemicals.

Subsets of ambient SEARCH samples were reanalyzed after differing storage periods to determine whether FT-IR handling and analysis, short-term storage and transport, or longterm storage had substantially affected the spectra. Changes in predicted functional group and $\mathrm{OM}$ concentrations over each period were compared to the sampling uncertainty to assess whether a measurable bias could be observed. The results of this reanalysis demonstrated that (1) duplicate analyses via FT-IR spectrometry were reproducible $(-3 \%$ median bias in OM concentrations) and FT-IR analysis did not impact filter sample composition, but (2) decreases in some functional group concentrations for some samples were measurable within the first year or two after sampling (e.g., approx. $-10 \% \mathrm{yr}^{-1}$ and $-5 \% \mathrm{yr}^{-1}$ median bias in $\mathrm{aCOH}$ and OM concentrations, respectively); however, (3) samples sta- bilize in storage and no longer had measurable concentration changes after several years (approx. $5 \%$ median bias measured between 7 years and 5 years after collection). Additional information about the reanalyses is summarized in Sect. S16.

\subsection{Outlier detection and handling}

Outlier laboratory standards and blanks were identified, and data were removed or set aside during the calibration process so that models were constructed and evaluated based on data with minimal errors. Laboratory standards and blanks with the following characteristics were explored as potential outliers: (1) unusually strong water vapor absorption bands in the spectra, (2) uncharacteristic and atypical chemical absorption bands in the spectra, (3) atypical molar absorptivities compared to other laboratory standards, or (4) collected material weights that were too high or essentially zero (except for blanks). Spectra with anomalously high leverage values (those which disproportionately impacted the model result; Hoaglin and Welsch, 1978) were also examined.

Ambient samples and field blanks are expected to be occasionally anomalous: for example, filters can be ripped, and field blanks can be swapped with ambient samples. Potential outlier ambient samples and field blanks were identified using a variety of methods. We treated the confirmed sample outliers in two ways. If no explanation for poor data quality could be determined, the spectrum was set aside into the validation set (see Sect. 2.5) and not used in the model construction process. Functional group concentrations of these spectra were measured and reported after model construction. If an explanation for poor data quality was determined, the spectrum was excluded from the analyses entirely.

We identified and further explored ambient samples with the following characteristics as potential outliers: (1) a spectrum that was visibly anomalous (e.g., swapped with a blank, having a hole, or having strong water vapor absorption bands), (2) a spectrum corresponding to a high TOR OC 
concentration but low infrared absorption, or (3) a high error in prediction after calibration. Principal component analysis (PCA), a technique used to find the patterns describing maximum variance in a dataset (Naes et al., 2002), was additionally used to identify potential outliers. Overall, approximately $8 \%$ (128 of 1656) of the ambient samples were removed from the dataset, and 31 were set aside for later prediction (in the validation set). Samples missing a TOR OC concentration were still included in the results.

\subsection{Building and evaluating the functional group calibration models}

Six functional group calibration models were initially constructed: saturated and aliphatic $\mathrm{C}-\mathrm{H}(\mathrm{aCH})$, unsaturated $\mathrm{C}-\mathrm{H}$ (unsCH), carboxylic acids $(\mathrm{COOH})$, oxalate $\mathrm{C}=\mathrm{O}$ (oxOCO), non-oxalate $\mathrm{C}=\mathrm{O}$ (noxCO), and alcohol $\mathrm{C}-\mathrm{OH}(\mathrm{aCOH})$. We used a linear regression between $\mathrm{COOH}$ and noxCO to differentiate between carboxylic $\mathrm{C}=\mathrm{O}$ and "naCO" (nonacid, non-oxalate, or other $\mathrm{C}=\mathrm{O}$; see Sect. S11 and Takahama et al., 2013). This was necessary because, although the $\mathrm{C}=\mathrm{O}$ stretching bands of carboxylic acids are theoretically shifted to lower wavenumbers $\left(\sim 1700-1710 \mathrm{~cm}^{-1}\right)$ than an unperturbed $\mathrm{C}=\mathrm{O}$ stretching band $\left(\sim 1725-1740 \mathrm{~cm}^{-1}\right.$; Mayo et al., 2003), there is not a clear separation between these two types of $\mathrm{C}=\mathrm{O}$ in spectra of particles and this spectral range is not unique to carboxylic acids. A calibration model for un$\mathrm{sCH}$ was developed, but we did not include the values in our results because a substantial fraction of the samples was below the detection limit (see Sect. 2.5.3). The five functional groups reported are therefore $\mathrm{aCH}, \mathrm{COOH}$, oxOCO, naCO, and $\mathrm{aCOH}$.

Although we used literature values as an initial estimate for the range of functional groups in the ambient samples, we further determined the maximum number of moles of each functional group to include in the models using a randomized energy minimization algorithm called simulating annealing (Ledesma et al., 2012; see Sect. S8-S9 for discussion on this method). The final values determined were $30 \mu \mathrm{mol} \mathrm{aCH}$ and unsCH, $5 \mu \mathrm{mol} \mathrm{COOH}, 4 \mu \mathrm{mol}$ oxOCO, $4 \mu \mathrm{mol}$ noxCO, and $10 \mu \mathrm{mol} \mathrm{aCOH}$.

Partial least-squares (PLS) regression was used for calibration and performed in Matlab using the nonlinear iterative partial least-squares (NIPALS) algorithm (Wold and Sjostrom, 2001). A mathematical description of PLS regression for functional group measurement is given in Reggente et al. (2019) and Ruthenburg et al. (2014). Briefly, PLS identifies a set of factors describing the variations in the laboratory standard spectra and known functional group moles, based on the maximal covariance between them. The spectral patterns of these factors (loadings) and the respective contributions of the factors to each standard spectrum (scores) are derived. The spectra and moles of functional groups in the calibration set of laboratory standards are mean-centered prior to use in the PLS model. A set of regression coeffi- cients, similar in concept to the slope of a univariate calibration curve, is calculated from the scores and loadings.

Laboratory and field data were partitioned into subsets for model development and application: (1) a calibration set of standards for training the calibration models, (2) a test set of standards used for testing the model parameters with respect to the response of laboratory standards, (3) a test set of ambient SEARCH samples for testing the model parameters with respect to bulk metrics such as residual OM and TOR OC, and (4) a validation set for evaluating model performance using the final model parameters. The calibration set of standards contained seven laboratory standards of each chemical, two chamber blanks per chemical, one method blank per chemical (56 total laboratory blanks), and $20 \%$ of the available SEARCH network field blanks (52). The test set of standards contained 1 to 14 standards per chemical (depending on the number of available standards) and the rest of the laboratory blanks (20) and field blanks (307). The test of samples set contained 1125 ambient samples and the same 307 test set field blanks. The validation set of samples contained 318 ambient samples, as well as extreme samples that were identified as possible outliers, but no explanation for their removal from the dataset was found ( 31 ; Sect. 2.4). The test and validation sets of ambient samples were combined for all figures and metrics.

The calibration set for each functional group model contained chemicals as organic "interferents" if the particular molecule did not contain that functional group, with quantities of functional group set to zero. This accounted for spectral overlap between functional groups. For example, carboxylic acids and alcohols were quantified separately, but both functional groups contain an $\mathrm{O}-\mathrm{H}$ bond absorbing in a similar mid-infrared range. Changing the number of such organic interferent standards in each model had a negligible impact on prediction.

Each functional group model was tested by applying it to the test set of laboratory standards using Eq. (1). The moles $(n)$ of each functional group $(g)$ in a laboratory standard $(j)$ with spectrum $x_{j}$ are measured as the sum of inner products with regression coefficients $b$ as follows:

$n_{i g}=\Sigma_{i j} b_{g j} x_{i j}$

The modeled moles of functional groups in the test set of laboratory standards (Eq. 1) were plotted against the known moles from filter weights. An orthogonal least-squares regression of the moles from the model and filter weights was fitted, and the median error, correlation coefficient, and slope were examined. Model inputs (such as the subset of laboratory standards included in the calibration versus test sets of standards, and the maximum quantity of each chemical in the calibration set laboratory standards) were altered to optimize the modeled test set of standards.

Multiple methods were tested to find the optimal number of factors for each SEARCH functional group model (see 
Sect. S8). The minimum root-mean-squared error of crossvalidation (RMSECV) with a $k$-fold of 3 was selected because of its speed and simplicity. Overfitting of the $\mathrm{COOH}$ functional group was observed (resulting in overestimation of naCO concentrations). To minimize this effect, the maximum number of factors was constrained to 15 for this model. All other functional groups were constrained to 25 factors. The resulting numbers of factors for each functional group calibration model selected by the automated minimum RMSECV method were 21, 25, 15, 24, 20, and 25 for aCH, un$\mathrm{sCH}, \mathrm{COOH}$, oxOCO, nox $\mathrm{CO}$, and $\mathrm{aCOH}$, respectively.

\subsubsection{Bulk OC and OM concentration estimates}

The concentration of $\mathrm{OC}$ in each ambient sample, $\mathrm{OC}_{i}$, was estimated as the sum of measured $\mathrm{C}$ atoms ("functional group OC"), assuming the following $\mathrm{C}$ atom contributions per functional group $\left(\lambda_{g}\right): \mathrm{aCH}=0.5 \mathrm{C}$; $\mathrm{COOH}=1 \mathrm{C}$; ox$\mathrm{OCO}=1 \mathrm{C}$; naCO $=1 \mathrm{C}$; and $\mathrm{aCOH}=0.5 \mathrm{C}$ (Eq. 2). The same values were used by Russell et al. (2003). For the four functional groups measured by Ruthenburg et al. (2014), the same assumptions were made, except that $\mathrm{aCOH}$ was assumed to contribute no C atoms. In Eq. (2), the moles of functional group $g$ in the $i$ th sample are denoted $n_{i g}$, and $12.011 \mathrm{~g} \mathrm{~mol}^{-1}$ is the molar mass of $\mathrm{C}$ :

$\mathrm{OC}_{i}=12.01 \Sigma_{g} n_{i g} \lambda_{g}$

These assumed values of $\lambda_{g}$ therefore influence the predicted functional group OC concentrations. The values of $\lambda_{g}$ are supported by parallel measurements and modeling (Takahama and Ruggeri, 2017), as well as Monte Carlo simulations (Burki et al., 2019). Similarly, OM concentrations were calculated from summed functional groups including the same assumptions for $\mathrm{C}$ contributions, plus all associated $\mathrm{O}$ and $\mathrm{H}$ atoms.

The OM/OC ratio was calculated by dividing the summed OM concentrations by the summed OC concentrations. Although TOR OC concentrations have been suggested for normalizing OM/OC ratios in the past (Reggente et al., 2019), the summed OC concentrations were used because these two values give a more consistent representation of organic composition than a ratio between an FT-IR spectrometry measurement and TOR measurement (these techniques capture slightly different portions of organic species or functional groups).

\subsubsection{Model evaluation: interpretation of model predictors and comparison with external measurements}

The variable importance in the projection (VIP) scores were calculated to simplify interpretation of the variance described by the calibration models. VIP scores have been previously utilized to demonstrate the importance of predictor variables (here, absorbance at each wavenumber) in PLS when the pre- dictor variables are not independent (Chong and Jun, 2005). This applies to the current method because in infrared absorption spectra absorbance at separate wavenumbers varies together (bonds can absorb in multiple regions simultaneously). Essentially, the VIP scores describe the relative importance of each wavenumber in the model by taking into account the $y$-variance (functional group quantity), explained by the model as weighted onto each PLS factor. The models were evaluated using the VIP scores by determining whether the important (and unimportant) wavenumbers in the models corresponded to known functional group absorption bands expected in ambient aerosols. See Sect. S12 for the equation used to derive the VIP scores for the total functional group OM.

Reference measurements to validate functional group concentrations directly do not exist: our measurements represent the first time these functional groups have been quantified in southeastern US aerosol samples to our knowledge. Instead, we evaluated our predictions against residual $\mathrm{OM}$ and TOR OC. The residual OM was calculated by subtracting the weighted sum of the major inorganic chemical constituents and elemental carbon from $\mathrm{PM}_{2.5}$ mass for each SEARCH sample using the equation described by Hand et al. (2012). A particle water correction was made (Dabek-Zlotorzynska et al., 2011; Simon et al., 2011). Metrics used between measured and reference OM or OC were coefficient of determination $R^{2}$, bias-corrected error (also known as the median absolute deviation, as previously described by Weakley et al., 2016), and orthogonal least-squares regression slope. Because the mass recovery was expected to be less than $100 \%$, bias was not a relevant metric. The $95 \%$ confidence intervals were calculated around the regression slope by bootstrapping. The regression slopes and confidence intervals gave an estimate of the mass recoveries of $\mathrm{OM}$ and $\mathrm{OC}$, relative to each reference method.

Another method for evaluating the model performance was comparing the data in a van Krevelen diagram to aerosol mass spectrometry data collected in the southeastern US. A van Krevelen diagram describes the overall elemental composition of $\mathrm{OM}$ in the two dimensional space of atomic $\mathrm{H} / \mathrm{C}$ versus atomic $\mathrm{O} / \mathrm{C}$. It should be noted that the material collected in the SEARCH network is $\mathrm{PM}_{2.5}$, and not $\mathrm{PM}_{1}$, as measured using aerosol mass spectrometry; however, the difference in sources contributing to OM between the two fractions may be small (Schum et al., 2018b). In the future, $\mathrm{PM}_{1}$ measurements could be considered for studying the comparison of FT-IR spectrometry and aerosol mass spectrometry measurements.

\subsubsection{Method detection limits}

The method detection limit (MDL) of each functional group concentration was estimated as 3 times the standard deviation of all laboratory and field blank functional group concentrations measured in the test set of standards. The MDL 
of the functional group OM and OC concentrations were estimated as the root of the sum of squares of the blank OM and $\mathrm{OC}$ concentrations predicted in the test sets. No samples were excluded from the results or plots based on the OM or OC MDLs. All ambient sample functional group concentrations predicted below the corresponding MDL were replaced with the value of $\mathrm{MDL}^{-2}$. This censoring technique has been applied in the past for multivariate analysis of environmental data (Polissar et al., 1998). When data were left uncensored, some values were negative, and therefore ratios such as the $\mathrm{OM} / \mathrm{OC}$ were misrepresented. Thus, although censoring of environmental data has obvious drawbacks (Helsel, 2005), the MDL-2 replacement and use of robust metrics such as median and percentiles were determined to provide the most accurate summary data. Samples with three or more functional group concentrations below the respective MDLs were not included in the $\mathrm{O} / \mathrm{C}$ and $\mathrm{H} / \mathrm{C}$ ratios (used in the van Krevelen diagram). This was done because in these cases the ratio was dominated by only one or two functional group contributions, and appeared as a straight line of datapoints on the van Krevelen diagram (and was not informative). These samples were, however, left in the dataset for all other figures and metrics so that the data were not biased toward higher functional group or OM concentrations.

\subsection{Model uncertainties}

The precision of the functional group measurement method was evaluated using two approaches, which attempted to evaluate some of the most substantial potential sources of uncertainty in the method. The first approach was the comparison of functional group concentrations measured from two colocated sampling sites within the SEARCH network ("sampling uncertainty"). The second approach was the calculation of confidence intervals (bootstrapped) around the functional group concentrations measured using a set of 18 model predictions, each of which had one organic chemical standard removed from the models ("chemical selection uncertainty").

The sampling uncertainty accounted for the sensitivity of the FT-IR spectrometry analysis procedure to differences in filter substrates, FT-IR analysis handling, and SEARCH network sampling and handling procedures. Sampling uncertainty was calculated (Hyslop and White, 2008, 2009) using measured functional group concentrations from the JST site and its colocated site, cJST. The colocated sampler was used to collect $\mathrm{PM}_{2.5}$ for only a subset of dates (2009-2011, October 2015, and 2016). This uncertainty was used throughout the study as the most complete estimate of method uncertainty, since it included most possible sources of uncertainty, aside from those arising from selection of model inputs and parameters.

The chemical selection uncertainty accounted for the possible impact of excluding a particular atmospherically important chemical from our models, within the bounds of our chemical list. We performed this "leave one out" analysis with the expectation that the sensitivity of the models would be similar between chemicals in the current models as well as some hypothetical, atmospherically important chemicals not included in the models. The chemical selection uncertainty was calculated as follows. A total of 18 sets of models were constructed, each excluding one organic chemical. Ambient functional group concentrations were measured using all models. For each functional group, the concentrations measured by all models were aggregated into one vector. The uncertainty over all samples and models was then determined using the sampling uncertainty equations between the "base case" concentrations (calculated with all chemicals included) and the "leave one out" concentrations.

\section{Results and discussion}

In the results that follow, we highlight how we addressed the multiple challenges of developing robust calibration models for measuring functional groups and $\mathrm{OM}$ concentrations in SEARCH ambient samples. In Sect. 3.1, the selected set of atmospherically relevant laboratory standards and the functional groups quantified are discussed. In Sect. 3.2, issues of molecular environment are qualitatively evaluated, including assessing humidity impacts and particle water absorbance. The accuracy of the models is dependent on model parameters and inputs; the model results were evaluated in Sect. 3.3 by confirming that predictive model spectral features were atmospherically relevant and predicted laboratory standards concentrations were accurate. Although functional group and OM concentrations cannot be directly compared to external (other method) measurements, Sect. 3.4 highlights comparisons used to evaluate and provide additional confidence in the model outputs. These include the fraction of OM quantifiable considering the portion that absorbs in the modeled spectral region (mass recovery), OM/OC ratios, and a van Krevelen diagram. Sect. 3.5 summarizes some additional uncertainties in the model and future work needed to address these.

\subsection{Chemicals used in the calibration models to concisely represent atmospheric composition}

Known atmospheric OM molecules are comprised mainly of a small number of functional groups, which include $\mathrm{C}$ $\mathrm{H}$, alcohol $\mathrm{O}-\mathrm{H}$, and various forms of $\mathrm{C}=\mathrm{O}$ groups. Relevant $\mathrm{C}=\mathrm{O}$ groups include carboxylic acids and carboxylates, as well as esters, ketones, and lactones. Multiple molecules that contain each of five important functional groups $\mathrm{aCH}$, $\mathrm{COOH}$, oxOCO, naCO, and $\mathrm{aCOH}$ ) were included in the calibration models in this work. Selections were made based on the known presence of a molecule in atmospheric OM or because the molecule exemplified the spectra of a functional group (Fig. 1; Table 1). Mass contributions from organic $S$ 
and $\mathrm{N}$ comprise a smaller portion of ambient OM (Liu et al., 2009; Stone et al., 2012) and were not included in this work. Substantial contributions of organosulfates to southeastern aerosol composition are possible (Hettiyadura et al., 2015), and the $\mathrm{OM} / \mathrm{OC}$ ratios of small organosulfate molecules are high; therefore, future models may consider such chemicals. The following paragraphs outline the atmospheric relevance and spectral features of each functional group reported in the current models.

The $\mathrm{C}-\mathrm{H}$ bond is ubiquitous in atmospheric organic molecules and is present in nearly all chemicals in the models (Table 1; Fig. 1). Fresh atmospheric emissions often contain abundant C-H bonds (e.g., alkanes from industrial and biogenic sources; Rogge et al., 1993), though C-H as a functional group should not be attributed only to fresh emissions since it is also plentiful in oxidized material (Schum et al., 2018b). Although minor in comparison to $\mathrm{C}=\mathrm{O}$ or $\mathrm{O}-\mathrm{H}$ stretching bands, there are some variations in the $\mathrm{C}-\mathrm{H}$ stretching bands (e.g., - $\mathrm{CH}_{2}$ - at 2926 asymmetric and 2853 symmetric $\pm 10 \mathrm{~cm}^{-1}$ for straight-chain alkanes, or 3085$2927 \mathrm{~cm}^{-1}$ asymmetric and $3028-2854 \mathrm{~cm}^{-1}$ symmetric in cyclic molecules; Mayo et al., 2003). A variety of C-H bonds were therefore selected for the models, including ring structures, short-chain and long-chain molecules (additional insight on the variation in $\mathrm{C}-\mathrm{H}$ bond absorption will be discussed in forthcoming work, Amir Yazdani, personal communication, 2018).

Saturated and unsaturated C-H bonds were quantified separately to distinguish between any differences in sources (e.g., Moretti et al., 2008). However, the concentrations measured using the unsCH model were not reported because a majority of sample concentrations measured were below the unsCH MDL. These measurements are realistic: low unsCH compared to $\mathrm{aCH}$ concentrations have also been observed in work using nuclear magnetic resonance (Moretti et al., 2008) as well as in previous FT-IR functional group calibration work (Guo et al., 2015; Liu et al., 2012; Russell et al., 2009b, 2011). Observed absorption coefficients of un$\mathrm{sCH}$ bonds were also low, consistent with theory (Mayo et al., 2003).

Carbonyls are a particularly informative functional group in infrared spectra of ambient OM due to their strong absorption coefficients and high abundance in the atmosphere. A strong, broad $\mathrm{C}=\mathrm{O}$ stretching band at $\sim 1700-1800 \mathrm{~cm}^{-1}$ is observed in ambient OM spectra (Takahama et al., 2013). In particular, molecules containing carboxylic acids may contribute the majority of OM mass (Decesari et al., 2007), the most abundant of which are typically the $\mathrm{C}_{2}-\mathrm{C}_{4}$ dicarboxylic acids (Kawamura and Bikkina, 2016). Six carboxylic acids were included in the calibration models. As in our previous work (Ruthenburg et al., 2014), malonic ( $\mathrm{C}_{3}$ dicarboxylic acid) and suberic acids $\left(\mathrm{C}_{8}\right.$ dicarboxylic acid) were included. The latter represents longer-chain carboxylic acids because it is spectrally similar to $\mathrm{C}_{16}$ and $\mathrm{C}_{18}$ monocarboxylic acids (National Institute of Advanced Industrial Science and Tech- nology, 2018). Oxalic $\left(\mathrm{C}_{2}\right.$ dicarboxylic) and succinic $\left(\mathrm{C}_{4} \mathrm{di}-\right.$ carboxylic) acids, which are often the most abundant organic species quantified in OM (Kawamura and Bikkina, 2016), were added to the current models. As a representative aromatic carboxylic acid, terephthalic acid was selected, originating from oxidation of burning plastics or other industrial activities (Wang et al., 2012). D-alanine, an amino acid, was also included.

Amines and amino acids have been studied in functional group calibrations (Kamruzzaman et al., 2018; Liu et al., 2009). Amines and amino acids could contribute $~ 5 \%$ $10 \%$ of organic aerosol concentrations and come from a variety of anthropogenic and biogenic sources (Russell et al., 2011). D-Alanine was included in the current models, differing from other carbonyl-containing spectra by its downshifted carboxylic $\mathrm{C}=\mathrm{O}$ stretching band (due to the electron donating power of the adjacent $\mathrm{N}$ atom) and $\mathrm{C}-\mathrm{N}$ stretching band in the same spectral region. These amino acid bands overlap with those of carboxylate $\mathrm{C}=\mathrm{O}$, but multivariate regression factors can account for other features of these functional groups to distinguish between them.

Although southeastern ambient aerosol particles may be acidic (Guo et al., 2015), concentrations of oxalate exceeding those of oxalic acid have been observed in ambient samples (Yang and Yu, 2008). Ammonium and sodium oxalates were therefore included in the models as example carboxylate salts, calibrated separately from the carboxylic acid functional group as oxalate carbonyl (oxOCO). The FT-IR spectra of ammonium and sodium oxalates were different from the spectra of oxalic and most other carboxylic acids, in that the $\mathrm{C}=\mathrm{O}$ stretching bands of carboxylate salts are below $1700 \mathrm{~cm}^{-1}$ (Fig. 1). Longer chain carboxylates such as succinates could contribute additional OM. The spectrum of ammonium oxalate also contains two N-H stretching bands overlapping with $\mathrm{O}-\mathrm{H}$ stretching bands and carboxylic sum tones at $3500-3100 \mathrm{~cm}^{-1}$, allowing the models to account for ammonium carboxylate interferences to measured $\mathrm{COOH}$ and $\mathrm{aCOH}$ concentrations.

Other, nonacid (and non-oxalate) carbonyls including esters, cyclic esters, and ketones could be abundant in atmospheric aerosol. Cyclic esters (lactones) within large, multifunctional molecules have been observed in ambient aerosol (Kahnt et al., 2018), and oxo-carboxylic acids such as cispinonic and pyruvic acids are frequently observed in ambient OM (Kawamura and Bikkina, 2016). These nonacid carbonyls were quantified in the models as "naCO", separate from carboxylic acids and oxalate, as in the work of Russell and co-workers (Frossard and Russell, 2012). The naCO was expanded in the present models to include not only a longchain ketone and ester but also a lactone (D-glucono-deltalactone) and a large, conjugated ketone-containing molecule (tannic acid). An aldehyde-containing molecule was also tested in the models, but the solubility of the particular chemical used (divanillin) limited the maximum mass collected onto filters (see also Sect. S4). The lactone was chosen to rep- 
(a)

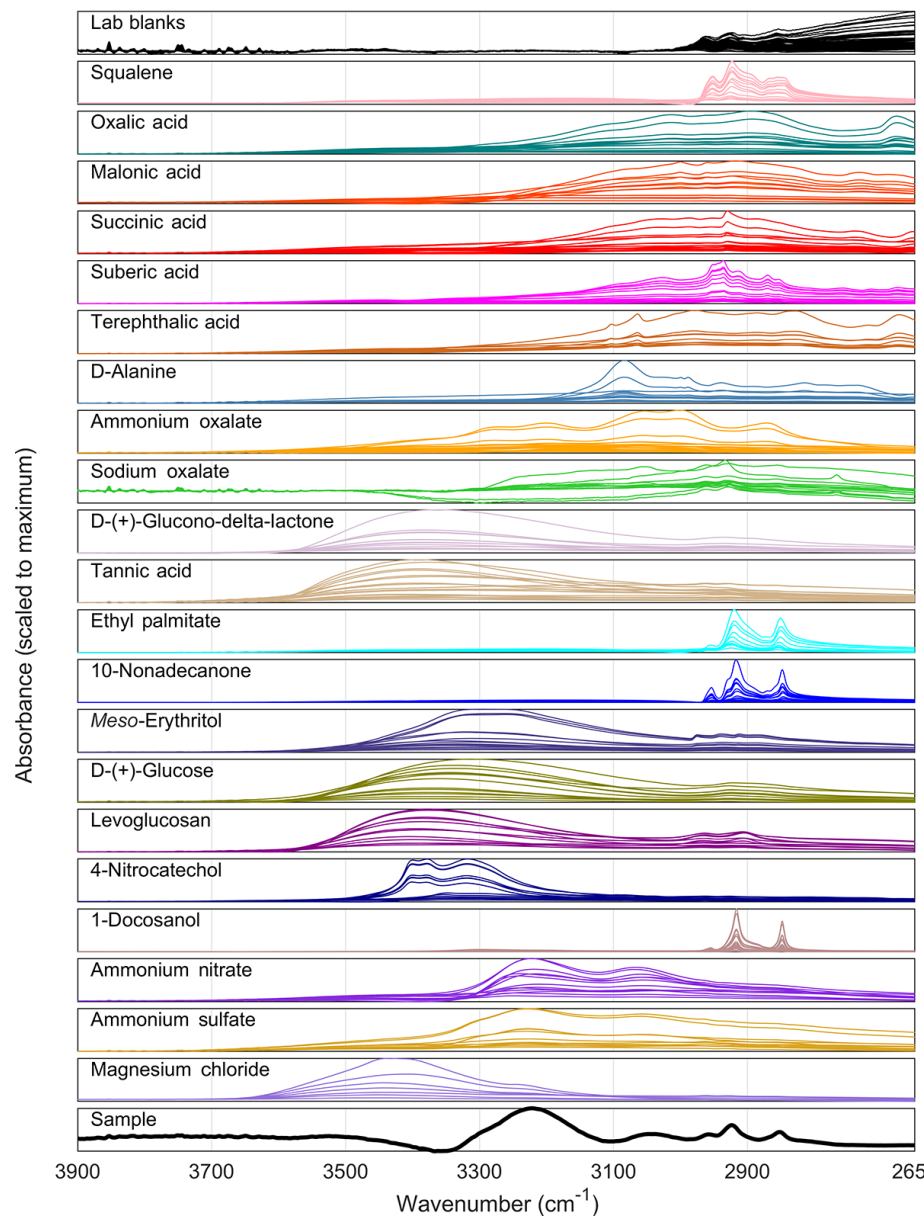

(b)

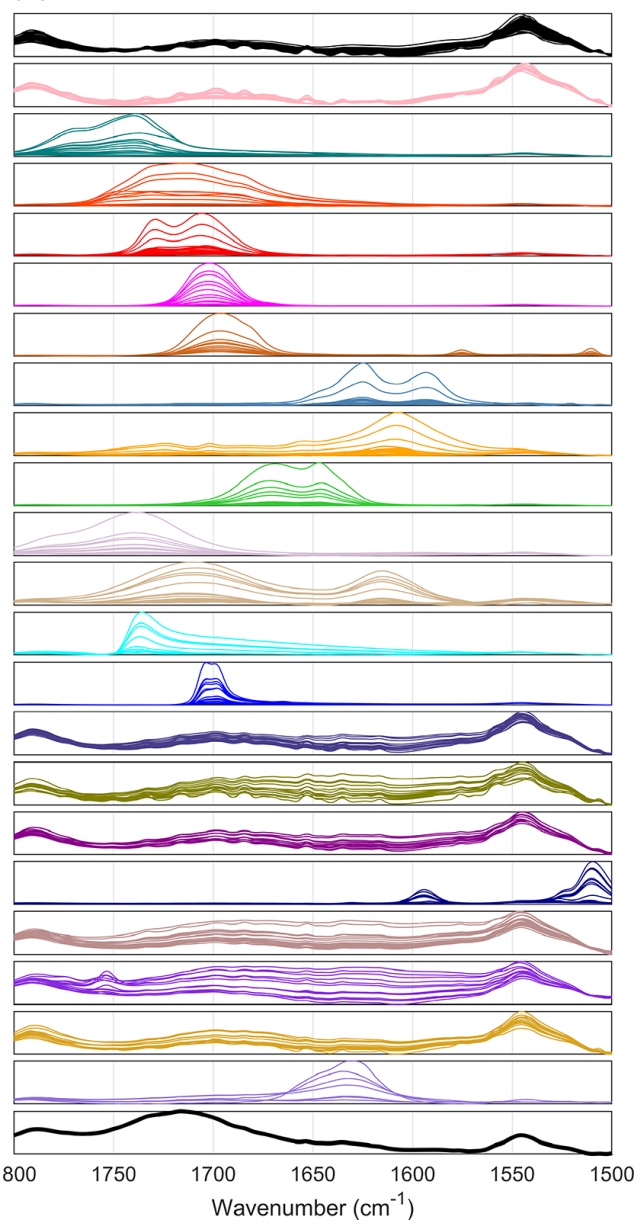

Figure 1. FT-IR spectra of all laboratory standards (calibration and test sets). The C-H, O-H, and N-H stretching region is plotted separately (a) from the $\mathrm{C}=\mathrm{O}$ and $\mathrm{C}=\mathrm{C}$ stretching region (b). An example ambient SEARCH sample spectrum is plotted for comparison (bottom subplot; 13 October 2013 from Birmingham, AL). Spectra are baseline-corrected via smoothing splines (Kuzmiakova et al., 2016), and each subplot is scaled to the maximum absorbance for each wavenumber range.

resent cyclic carbonyl structures such as carbohydrates and furanones (Hamilton et al., 2004). Tannic acid was included in the naCO functional group to represent larger, humic-like molecules. Its spectrum is characterized by a broad $\mathrm{C}=\mathrm{O}$ stretching band due to the movement of electrons through its multi-ring, oxygenated aromatic structure (Fig. 1; Table 1), similar to spectra of observed atmospheric humic-like material (Chen et al., 2016). The molecule is large relative to atmospheric components observed using typical ion and gas chromatography methods (Gao et al., 2006) and has a known chemical structure (unlike other humic-like candidate molecules). Note that tannic acid contains no $\mathrm{COOH}$ moieties but instead contains ester and ketone naCO, unsCH, $\mathrm{aCH}$, and phenolic aCOH.

Along with nonacid carbonyls, alcohol $\mathrm{OH}(\mathrm{aCOH})$ is often recognized as an intermediate within oxidation schemes because the $\mathrm{C}$ atom is not maximally oxidized (Heald et al., 2010). A variety of alcohol-containing molecules were in- cluded in the models, typified by broad hydrogen bonded O-H stretching bands $\sim 3500-3100 \mathrm{~cm}^{-1}$ (Fig. 1). mesoErythritol was included as a representative isoprene oxidation product, which is understood to be important in the southeast (Claeys et al., 2004). Phenols were represented by 4-nitrocatechol, which is most often associated with biomass burning and pesticide emissions (Harrison et al., 2005; tannic acid also contains phenol). Along with 4-nitrophenol, levoglucosan is an abundant tracer for biomass burning emissions (Mayol-bracero et al., 2002); it was also included in our previous work (Ruthenburg et al., 2014). Glucose was spectrally similar to levoglucosan but was included to represent carbohydrates from other sources such as fungal spores (Caseiro et al., 2007). Although there is little literature discussing long-chain alcohols in atmospheric aerosol, they are indeed present at low quantities (Rogge and Hildemann, 1994). 1-Docosanol was therefore included, as in the work of Ruthenburg et al. (2014). 
Three types of interferent molecules were included in each of the functional group models: inorganic salts, particle water, and interfering organic species. Ammonium nitrate and ammonium sulfate are abundant in atmospheric aerosol, and overlap spectrally (N-H stretching) with strongly absorbing organic molecule features, such as $\mathrm{O}-\mathrm{H}$ and $\mathrm{C}-\mathrm{H}$ stretching bands. Therefore, these inorganic salts were included as interferents in the models (ammonium nitrate was not included in the Ruthenburg et al., 2014 models). Water also contributes some $\mathrm{O}-\mathrm{H}$ stretching to aerosol spectra (Frossard and Russell, 2012), so a hygroscopic inorganic salt with negligible inorganic absorption stretches, magnesium chloride $\left(\mathrm{MgCl}_{2}\right)$, was also included in the models. To our knowledge, particle water has not been previously accounted for as an interferent in functional group measurements by PLS calibration of FT-IR spectra, although water interference has been discussed and explored in peak fitting calibrations (Faber et al., 2017; Frossard and Russell, 2012). The result of including particle water as an interferent in the calibration models (collected as $\mathrm{MgCl}_{2}$ ) was the contribution of spectral features to the models associated with particle water (demonstrated in the VIP scores; see Sect. S12). No substantial changes in the measured functional group concentrations (including that of $\mathrm{aCOH})$ or the predicted OM concentrations were observed due to the inclusion of particle water standards (Sect. S6). This is probably because the humidity in the FT-IR spectrometer sample chamber is low $(0 \%-10 \%)$. Particle water was therefore limited to liquid water in un-effloresced highly hygroscopic particles, hydrate water, or as embedded water under aerosol material layers (Frossard and Russell, 2012).

\section{Addressing uncertainty in model chemical selection}

While the chemicals used in the calibration models were selected carefully, using current literature of atmospheric composition, such a concise list will inherently bring about some uncertainty. To demonstrate the robustness of our models to chemical selection, we examined the effect of leaving one chemical at a time out of our calibration models (see Sects. 2.6 and S18). The resulting precision related to chemical selection was within the same range as that calculated for sampling uncertainty $(10 \%-30 \%$ bias in median functional group concentrations; Sect. 3.2.2). The greatest change in predicted functional group concentrations was observed for oxOCO: when either ammonium or sodium oxalate was left out during model construction, the oxOCO model was not robust to the change. This was likely due to the small number of chemicals included in the functional group model (only two) and enhanced by the difference between the spectra of these two chemicals, which contained broad features that overlapped with those of other functional groups. The predicted median OM concentration decreased by $\sim 25 \%$ when oxOCO was not included as a functional group in the models, a change that was attributed not only to the influence of these two spectrally distinct standard chemicals but also to the influence of oxOCO standards as "interferents" in models of other functional groups. Interpretation of the predictive spectral features (VIP scores; see Sect. 3.3.1) suggested that the spectral features of oxOCO that overlap with those of other functional groups, when unaccounted for in the models, obscured those features from being fully captured by the models. Thus, by including the additional spectral information of oxOCO standards as interferents in the other functional group models, other functional groups were more fully and clearly measured.

\subsection{Molecular environment considerations}

Aspects of the environment within and around collected standard particles were examined to discern whether the conditions were relevant to simulated ambient aerosol samples. In particular, three types of molecular-level interactions with the particles of the collected laboratory standards were considered: (1) hydrogen bonding patterns within pure chemicals, (2) hydrogen and ionic bonding within mixtures of two different chemicals, and (3) changes of pure chemicals due to exposure to water.

The organization and orientation of polar organic molecules within solid particles is dictated in part by the intermolecular or intramolecular hydrogen bonding interactions between $\mathrm{H}$ and $\mathrm{O}$ atoms (and possibly other electronegative atoms). These hydrogen bonding patterns can strongly influence infrared spectra, causing splitting, broadening, or frequency shifts in absorption bands (Davey et al., 2006). Dimeric or polymeric hydrogen bonding structures of carboxylic acid standards in the present work were confirmed by the broad $\mathrm{O}-\mathrm{H}$ stretching band between approximately 3200 and $2600 \mathrm{~cm}^{-1}$ (with overlaid sum tone absorption bands) and the presence of out-of-plane $\mathrm{O}-\mathrm{H}$ wagging bands between 950 and $850 \mathrm{~cm}^{-1}$ (Mayo et al., 2003). Similar hydrogen bonding $\mathrm{O}-\mathrm{H}$ stretching bands were observed for most alcohols, at higher frequencies due to their weaker hydrogen bonding than carboxylic acids (Mayo et al., 2003). If O$\mathrm{H}$ bonds are unassociated with other polar groups, free $\mathrm{O}-\mathrm{H}$ stretching peaks are present in an FT-IR spectrum (Davey et al., 2006; Mikhailov et al., 2009). This was observed in the standards of single, pure chemicals containing multiple polar, oxygenated functional groups, including tartaric acid (not included in models; see discussion and spectra in Sect. S4) and 4-nitrocatechol spectra. Free O-H stretching bands were not clearly observed in the SEARCH ambient sample spectra but could have contributed low absorbance within the sample mixture. Hydrogen bonding within the likely amorphous solid structures of ambient particles (Mikhailov et al., 2009) and the dimeric or polymeric polar protic chemical used in the calibration were generally consistent.

Laboratory standard filters used for (quantitative) calibration included one chemical on each filter, but hydrogen or ionic bonding interactions between the many chemicals in ambient aerosol samples were expected. We therefore gen- 
erated laboratory standards with mixtures of pure chemicals, including combinations of two carboxylic acids (malonic with terephthalic acid and malonic acid with succinic acid), carboxylic acids with alcohols (succinic or malonic acids with meso-erythritol and malonic acid with levoglucosan), and an inorganic salt with carboxylic acids (ammonium nitrate with terephthalic acid, succinic acid, or malonic acid). Hydrogen bonding interactions were observed (see Sect. S7, Fig. S8) in some mixtures, such as those of mesoerythritol with malonic and succinic acids, which resulted in the splitting or broadening of the $\mathrm{O}-\mathrm{H}$ stretching band of meso-erythritol (likely due to the formation of additional hydrogen bonding environments). No substantial changes to the $\mathrm{C}=\mathrm{O}$ stretching bands were observed. No interactions were visible in the FT-IR spectra between inorganic salts and carboxylic acids or between some of the mixed polar protic species, such as malonic acid with terephthalic acid. Oxalate standards, as discussed earlier in Sect. 3.1, accounted for carboxylate salt (ionic bonded OM) contributions to OM concentrations. Based on these observations, models constructed with pure chemical standards could be misattributing some spectral features (adding some error and scatter or bias via overprediction or underprediction) but, seemingly, only for some functional groups and some molecular interactions.

The influence of water exposure on laboratory standards was examined to demonstrate possible differences between ambient and laboratory-generated particles. Although chemical effects were anticipated, including addition of water to nonacid carbonyl groups to form gem-diols or changes in hydrogen bonding structure after deliquescence, there was no spectral evidence of either. Instead, an irreversible decrease in laboratory standard infrared absorption occurred when hygroscopic species were exposed to humid conditions (glucose, ammonium sulfate, and pyruvic acid; see Sect. S6 and Fig. S5). This was likely the result of a redistribution of collected material away from the infrared beam: there was no consistent and significant change in the weight of standard filters, and a similar decrease in infrared absorption was not observed for the hydrophobic species squalene. Some additional water vapor absorption was also observed. The dry ( $\sim 0 \%-10 \%$ relative humidity) environment of the FTIR spectrometer sample chamber was also examined by exposing laboratory standards to a dry environment; no effect on the spectra was observed. Particle water laboratory standards $\left(\mathrm{MgCl}_{2}\right)$ were included in the calibration models, as described earlier in Sect. 3.1, and effectively accounted for the known portion of particle water (Dabek-Zlotorzynska et al., 2011; Faber et al., 2017).

\subsection{Evaluation of model performance}

\subsubsection{Predictive features of laboratory standards found in the models}

We first evaluated model performance by interpreting the spectral features in the models used to measure each functional group. Variable Importance in the Projection (VIP) scores of the predicted OM, shown in Fig. 2, demonstrate the predictive spectral features from the laboratory standards (see Sect. S12 for the calculation, including the method for weighted summing of functional group contributions to VIP scores). A value of one was chosen as a threshold for significant VIP scores, after Chong and Jun (2005) and Weakley et al. (2016).

Spectral features in the VIP scores matched those in absorbing ambient OM but were absent where inorganic species or Teflon absorb in the ambient sample spectra, despite the thick filter material and low aerial density of SEARCH aerosol samples relative to IMPROVE samples (used in Ruthenburg et al., 2014). This suggests that the list of chemicals assembled and used in the present calibration models approximated atmospheric composition (a challenge outlined in Sect. 1.3). In addition, including inorganic interferents such as ammonium nitrate and ammonium sulfate successfully allowed the models to avoid accounting for the related spectral features as OM. Predictive features, as determined using the VIP scores and described below, include absorption bands associated with nonacid carbonyls, carboxylic acids, oxalates, D-alanine, alcohols, methylene $\mathrm{C}-\mathrm{H}$, and unsaturated $\mathrm{C}=\mathrm{C}$ bonds.

Among the most prominent of the features in the VIP scores are several oxygenated functional group bands. Significant VIP scores $(>1)$ are observed in the $\mathrm{C}=\mathrm{O}$ stretching region, corresponding to overlapping absorption bands in the laboratory standards of ethyl palmitate, $\mathrm{D}-(+)$-gluconodelta-lactone and oxalic acid at $\sim 1700 \mathrm{~cm}^{-1}$, while at $1735 \mathrm{~cm}^{-1}$, malonic and succinic acids, D- $(+)$-gluconodelta-lactone, tannic acid, and ethyl palmitate may contribute variance. Features specifically associated with $\mathrm{D}$-alanine $(\sim$ 1625 and $1590 \mathrm{~cm}^{-1}$ ) and with oxalates (sodium oxalate at $1650 \mathrm{~cm}^{-1}$ and ammonium oxalate at $1610 \mathrm{~cm}^{-1}$ ) were observed at the low end of the $\mathrm{C}=\mathrm{O}$ stretching region. Two bands with ambiguous interpretation were observed at $\sim$ 3090 and $\sim 3000 \mathrm{~cm}^{-1}$. These two peaks could be associated with malonic acid $\mathrm{O}-\mathrm{H}$ stretching and overlaid sum tones or with the N-H bonds of ammonium oxalate and/or D-alanine. Between 3410 and $3310 \mathrm{~cm}^{-1}$, the distinct, sharp $\mathrm{O}-\mathrm{H}$ stretching features of the 4-nitrocatechol spectra were likely predictive and were observed near a VIP score of 1 .

Aliphatic and unsaturated carbon backbone features were identified among the significant spectral characteristics, based on laboratory standard spectral features. The asymmetric methyl $\left(2950 \mathrm{~cm}^{-1}\right)$, as well as asymmetric and symmetric methylene $\left(-\mathrm{CH}_{2-} ; 2920\right.$ and $\left.2850 \mathrm{~cm}^{-1}\right)$ stretching bands 

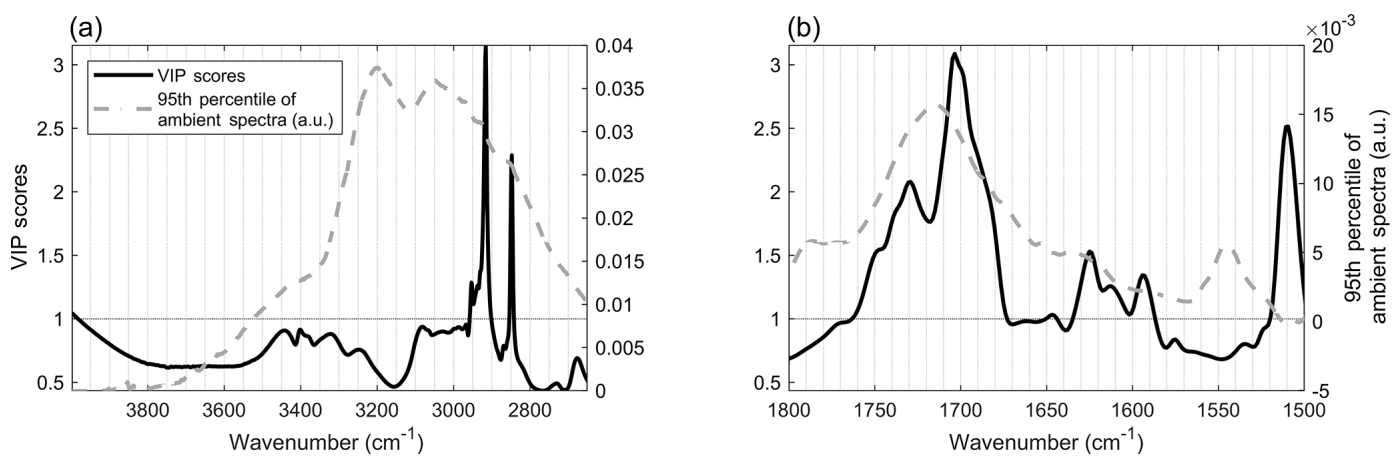

Figure 2. Variable importance in the projection (VIP) scores generated from the calibration models, as a weighted sum of the functional groups (Sect. S12, for calculation). An ambient spectrum is superimposed for comparison (95th percentile of all ambient spectra).

were prominent, as was the $\mathrm{C}=\mathrm{C}$ aromatic bending band $\left(1510 \mathrm{~cm}^{-1}\right)$.

Several features in the ambient spectra (demonstrated here as the 95th percentile of ambient SEARCH spectra, dashed grey trace in Fig. 2) were not visible in the VIP scores, indicating that they were not predictive for OM. For example, the symmetric $\mathrm{N}-\mathrm{H}$ stretching peaks of inorganic (and possibly carboxylate) ammonium at $\sim 3200$ and $\sim 3050 \mathrm{~cm}^{-1}$ are visible in the ambient spectral trace but not the VIP scores. Likewise, the fine water vapor absorption features above $3400 \mathrm{~cm}^{-1}$ and the PTFE absorption features at $\sim 1780$ and $1545 \mathrm{~cm}^{-1}$ in the ambient spectra were not predictive. Note, however, that the sloping baseline above $\sim 3900 \mathrm{~cm}^{-1}$ was predictive, which could indicate that light scattering by the particulate material on each filter (Weis and Ewing, 1996) was a predictive feature of the laboratory standards.

\subsubsection{Summary of functional group calibration model metrics}

Selecting appropriate model parameters based on our current understanding was a major challenge in the current study and was addressed through various model iterations and considerations. The final model parameters and metrics of the results for the five functional groups reported $\mathrm{aCH}, \mathrm{COOH}$, oxOCO, naCO, and $\mathrm{aCOH}$ ) are summarized in Table 2.

As noted in Sect. 2.5, the naCO concentrations could not be calibrated directly because of spectral overlap and were instead determined by partitioning excess noxCO relative to $\mathrm{COOH}$ concentrations (Sect. S11). The final two rows of the table give the prediction metrics for OM and OC, which were derived from the five reported functional groups (see Sect. 2.5). The dynamic ranges of laboratory standards used in each functional group model were inclusive of, and similar to, the range of concentrations measured within the ambient samples: for example, aCH concentrations ranged from 0.002 to $1.2 \mu \mathrm{g} \mathrm{m}^{-3}$ in laboratory standards and from 0.02 to $0.46 \mu \mathrm{g} \mathrm{m}^{-3}$ in the samples (1st to 99th percentiles of sample concentrations). This demonstrated the success of using previous literature and simulated annealing to select the max- imum functional group concentrations in the models (see Sect. 2.5), one aspect of the major challenges anticipated in this work. Likewise, other parameters such as the number and type of non-interfering chemicals included in each model, as well as the number of PLS model factors, were explored in depth by examining the atmospheric likelihood of results when iterating manually over those parameters. As described in Sect. 2.5, many methods for selecting the number of PLS factors were tested, and RMSECV was used because of its flexibility and simplicity.

The correlations between the functional group moles measured via FT-IR spectrometry and gravimetric analysis for laboratory standards were strong: $R^{2} \geq 0.93$ for all calibrated functional groups. Normalized errors in prediction for the test sets were $7 \%-16 \%$, and slopes of the crossplots were 0.91-1.05 for all calibrated functional groups (see Figs. S13 and S14). As expected, some ambient sample functional group concentrations were below MDLs. However, for all reported functional groups, the median concentration measured in the ambient samples was greater than the MDL (Table 2). The predicted median concentrations of OM and $\mathrm{OC}$ in the ambient samples were well above the respective MDLs and $\sim 80 \%$ of the ambient sample predicted concentrations were greater than the MDLs for OM and OC. Note that the values discussed in this paragraph were calculated before the censoring of the data below functional group MDLs, as discussed in Sect. 2.5.2.

Sampling uncertainty (Sect. 2.6) was $14 \%\left(0.39 \mu \mathrm{g} \mathrm{m}^{-3}\right)$ for OM and $14 \%\left(0.19 \mu \mathrm{g} \mathrm{m}^{-3}\right)$ for OC (Table 2). These low sampling uncertainty values demonstrated that (a) the filter sampling, handling, and storage methods were reproducible and that (b) the functional group calibration procedures were reproducible.

\subsection{Evaluation by comparison to other methods and previous FT-IR spectrometry work}

There are scarce measurements of functional groups to validate the FT-IR-PLS method developed here. We address this challenge by instead corroborating our measurements with 
Table 2. Summary of calibration model parameters and outputs. Functional groups calibrated but not reported in the final models are also included, below the first horizontal line.

\begin{tabular}{|c|c|c|c|c|c|c|c|c|c|c|}
\hline $\begin{array}{l}\text { Functional } \\
\text { group }\end{array}$ & Method & $\begin{array}{r}\text { Dynamic } \\
\text { range }\end{array}$ & $\begin{array}{r}\text { Ratio } \\
(\lambda)^{2}\end{array}$ & $\begin{array}{l}\text { Num. } \\
\text { chems. }\end{array}$ & $\begin{array}{r}\text { Factors } \\
(\mathrm{RMSECV})\end{array}$ & $\begin{array}{r}\text { Standards test } \\
\text { set coef. of } \\
\text { det. }\left(R^{2}\right)\end{array}$ & $\begin{array}{r}\mathrm{MDL} \\
\left(\mu \mathrm{g} \mathrm{m}^{-3}\right)\end{array}$ & $\begin{array}{r}\text { Percentage of } \\
\text { ambient samples } \\
\text { above MDL }(\%) \\
\left(\mu \mathrm{g} \mathrm{m}^{-3}\right)\end{array}$ & $\begin{array}{r}\text { Median } \\
\text { concentration } \\
\text { in samples }\end{array}$ & $\begin{array}{r}\text { Sampling } \\
\text { uncertainty } \\
\left(\mu \mathrm{g} \mathrm{m}^{-3}, \%\right)^{4}\end{array}$ \\
\hline $\begin{array}{l}\text { Saturated } \\
\text { hydrocarbon } \\
(\mathrm{aCH})\end{array}$ & Calibrated & $\begin{array}{r}0.002 \text { to } \\
1.2\end{array}$ & 1 & 13 & 20 & 0.99 & 0.26 & 94 & 0.90 & $0.15,16 \%$ \\
\hline $\begin{array}{l}\text { Carboxylic } \\
\text { acids } \\
(\mathrm{COOH})\end{array}$ & Calibrated & $\begin{array}{r}0.04 \text { to } \\
3.3\end{array}$ & 1 & 6 & 15 & 0.98 & 0.26 & 84 & 0.63 & $0.15,28 \%$ \\
\hline $\begin{array}{l}\text { Oxalate } \\
\text { carbonyl } \\
\text { (oxOCO) }\end{array}$ & Calibrated & $\begin{array}{r}0.07 \text { to } \\
0.65\end{array}$ & 1 & 2 & 23 & 0.93 & 0.04 & 99 & 0.27 & $0.04,18 \%$ \\
\hline $\begin{array}{l}\text { Nonacid } \\
\text { carbonyl } \\
\text { (naCO) }\end{array}$ & Partitioned & - & 1 & - & - & - & 0.04 & 92 & 0.25 & $0.08,26 \%$ \\
\hline $\begin{array}{l}\text { Alcohol } \\
(\mathrm{aCOH})\end{array}$ & Calibrated & $\begin{array}{r}0.04 \text { to } \\
7.0\end{array}$ & 0.5 & 7 & 25 & 0.98 & 0.24 & 88 & 0.60 & $0.13,25 \%$ \\
\hline $\begin{array}{l}\text { Unsaturated } \\
\text { hydrocarbon } \\
(\text { unsCH) }\end{array}$ & Calibrated & $\begin{array}{r}0.002 \text { to } \\
0.39\end{array}$ & 0.5 & 4 & 25 & 0.99 & 0.08 & 12 & 0.04 & $0.03,21 \%$ \\
\hline $\begin{array}{l}\text { Non-oxalate } \\
\text { carbonyl } \\
\text { (noxCO) }\end{array}$ & Calibrated & $\begin{array}{r}0.04 \text { to } \\
2.6\end{array}$ & - & 10 & 19 & 0.98 & 0.10 & 99 & 0.64 & $0.04,18 \%$ \\
\hline $\begin{array}{l}\text { Organic matter } \\
(\mathrm{OM})\end{array}$ & $\begin{array}{l}\text { Predicted } \\
\text { as sum }\end{array}$ & - & - & 20 & - & - & 0.45 & 80 & 2.1 & $0.38,14 \%$ \\
\hline $\begin{array}{l}\text { Organic carbon } \\
(\mathrm{OC})\end{array}$ & $\begin{array}{l}\text { Predicted } \\
\text { as sum }\end{array}$ & - & - & 20 & - & - & 0.25 & 81 & 1.0 & $0.19,14 \%$ \\
\hline
\end{tabular}

multiple qualitative and quantitative metrics from separate methods. We evaluate the model results by comparing to bulk measurements including residual $\mathrm{OM}$ concentrations; TOR OC concentrations; and ratios of $\mathrm{OM} / \mathrm{OC}, \mathrm{O} / \mathrm{C}$, and $\mathrm{H} / \mathrm{C}$ from other techniques. Expected trends between urban and rural pairs, seasons, and functional groups, based on previous research, were also used.

\subsubsection{Evaluating FT-IR measurements: mass recovery}

The concentrations of functional group $\mathrm{OM}$ and $\mathrm{OC}$ were not expected to be $100 \%$ of the actual concentrations in ambient samples because some bonds do not absorb mid-infrared light within the modeled range $\left(4000-1500 \mathrm{~cm}^{-1}\right)$. For example, squalene $\left(\mathrm{C}_{30} \mathrm{H}_{50}\right)$ contains five $\mathrm{C}$ atoms per molecule with only $\mathrm{C}-\mathrm{C}$ bonds; those five $\mathrm{C}$ atoms do not absorb in the mid-infrared range, so squalene $\mathrm{OC}$ concentrations will be underestimated by $17 \%$. Similarly, levoglucosan $\left(\mathrm{C}_{6} \mathrm{H}_{10} \mathrm{O}_{5}\right)$ contains two $\mathrm{O}$ atoms within its rings; since the stretching region of C-O is at $1300-1000 \mathrm{~cm}^{-1}$ (Pavia et al., 2009), where PTFE also absorbs, functional group OM will underestimate levoglucosan $\mathrm{OM}$ by $\sim 20 \%$. Thus, in the prediction of OM or OC in ambient samples, a "mass recovery" of approxi- mately $70 \%-80 \%$ OM or OC was expected (Takahama and Ruggeri, 2017). In addition, since the composition of ambient samples varies, the mass recoveries were expected to differ, and thus to add scatter to the comparison of FT-IR OM and OC concentrations to more routine measurements. Quantifying a substantial fraction of the OM (and OC), despite the lack of mid-infrared absorption of some relevant molecular bonds, was a major challenge in this current work, addressed by chemical and model input selection.

Other methods of OM or OC characterization are understood to have a mass recovery below $100 \%$. Similar to FTIR-PLS, the mass recovery of organics in aerosol mass spectrometry is $75 \%$ for $\mathrm{O} / \mathrm{C}$ ratios and $91 \%$ for $\mathrm{H} / \mathrm{C}$ ratios (Aiken et al., 2008; assuming constant collection and relative ionization efficiencies with particle composition). A study comparing simultaneous characterization of OM composition found that the FT-IR spectrometry OM concentrations were $20 \%-40 \%$ lower than those observed using aerosol mass spectrometry, within the combined uncertainties of the methods ( $\sim 20 \%$ for each method; Liu et al., 2018). Although TOR OC mass recovery from the filters is expected to be $100 \%$ based on analysis of organic standards, the OC/EC 
split into thermal-optical carbon analysis methods may introduce uncertainty into the TOR OC concentration (Chow et al., 2004). Approximate corrections for TOR and quartz sampling artifacts are made by various methods including using denuders and backup filters and by subtracting blank OC concentrations, as in the IMPROVE and SEARCH networks (Chow et al., 2015). Residual OM, as discussed earlier, encompasses substantial uncertainties due to various inputs such as particle water and nitrate sampling artifacts (Chow et al., 2015). Each method used in the present work to evaluate the FT-IR model results therefore has a mass recovery below $100 \%$ (as does the FT-IR-PLS calibration method) but approximates the total OM or OC concentration.

The mass recoveries of OM and OC measured by FT-IR spectrometry were evaluated by comparison with residual OM and TOR OC, respectively. The OM mass recovery (versus residual $\mathrm{OM}$ ) was $81 \pm 5 \%$ ( $\pm 95 \%$ confidence interval), estimated as the orthogonal least-squares slope of the regression between the two OM estimates (Fig. 3).

The correlation between the functional group and residual OM concentrations was strong $\left(R^{2}=0.82\right)$, with a biascorrected error of $16 \%$ (Fig. 3), demonstrating that the modeled OM concentrations in the SEARCH ambient samples were consistent with, and accounted for most of, residual OM. Similarly, functional group OC accounted for $71 \pm 8 \%$ of TOR OC and was correlated with TOR OC concentrations $\left(R^{2}=0.74\right)$, with a bias-corrected error of $17 \%$. The mass recovery observed in this work is similar to that in previous FT-IR spectrometry measurements (Takahama and Ruggeri, 2017).

\subsubsection{Evaluating FT-IR measurements: $O M$ and functional group concentrations}

The median concentrations of OM estimated as the sum of functional groups were within the range of those measured previously using aerosol mass spectrometry and FTIR spectrometry $\left(\sim 1-10 \mu \mathrm{g} \mathrm{m}^{-3}\right.$; Kamruzzaman et al., 2018; Ruthenburg et al., 2014; Sun et al., 2011; Xu et al., 2015.). The absolute median OM concentrations were greater at urban sites (JST, BHM) than at rural sites (CTR, YRK, OLF), as anticipated. Overall, OM contributed $\sim 35 \%$ of $\mathrm{PM}_{2.5}$ mass in the 2009-2016 SEARCH samples, ranging typically between $20 \%$ and $60 \%$ (interquartile range). Similarly, Gao et al. (2006) found that $\sim 32 \%, \sim 37 \%$, and $\sim 43 \%$ of $\mathrm{PM}_{2.5}$ mass at BHM, JST, and CTR, respectively, were contributed by OM in summer 2004 (estimated using TOR OC concentrations and $\mathrm{OM} / \mathrm{OC}$ ratios of 1.6 at the urban sites and 2.0 at (TR).

The concentrations of functional groups measured in ambient samples (Fig. 4, left panel) were as follows. Functional group contributions to OM in SEARCH samples included $\sim 25 \%-45 \%$ aCH by mass. This large fraction was expected since nearly every molecule in organic aerosol contains $\mathrm{aCH}$. The even larger contribution of oxygenated func- tional groups to $\mathrm{OM}$ agreed with expectations that southeastern US aerosol would be highly oxidized relative to OM from other parts of the country (e.g., Simon et al., 2011). Carboxylic acids, followed by alcohols, were the oxygenated functional groups that contributed most substantially to the OM concentrations $(\sim 20 \% \mathrm{COOH}-30 \% \mathrm{COOH}$ and $\sim 15 \% \mathrm{aCOH}-30 \% \mathrm{aCOH})$. It is unsurprising that the latter functional groups were abundant in the samples, based on previous work in general (Kawamura and Bikkina, 2016) and in the southeastern US in particular (Gao et al., 2006). The median contributions of $\mathrm{COOH}$ to $\mathrm{OM}$ concentrations were lower at the urban sites than the rural sites, which can be attributed to the fresher emissions typically sampled at urban sites. Nonacid carbonyls also contributed 5\%-20\%, and oxOCO contributed $5 \%-10 \%$ of OM by mass; oxOCO concentrations were equivalent to $\sim 40 \%$ of $\mathrm{COOH}$ concentrations (interquartile range $36 \%-54 \%$ ). Data from all analyzed SEARCH years will be further detailed in a forthcoming paper on trends in the southeastern US, but data from 2013 are discussed briefly here to demonstrate model improvements, since there are FT-IR spectrometry measurements using previous FT-IR functional group models (Kamruzzaman et al., 2018) in that year.

The functional group composition of $\mathrm{OM}$ at the IMPROVE site in Birmingham, Alabama, as measured using the previous FT-IR spectrometry models (Fig. 4b), was compared to the colocated SEARCH BHM samples (concentrations measured using the current models). Median $\mathrm{OM}$ concentrations at Birmingham were greater using the current models $\left(3.1 \pm 2.8 \mathrm{\mu g} \mathrm{m}^{-3}\right)$ than the 2014 models $\left(2.1 \pm 2.0 \mathrm{\mu g} \mathrm{m}^{-3}\right)$ by $48 \%$. The greater OM concentrations predicted by the current models can be explained mainly by enhanced oxygenated functional group concentrations: while the contributions of $\mathrm{aCH}$ to $\mathrm{OM}$ concentrations were lower at Birmingham using the current model predictions (median concentrations were $1.20 \mu \mathrm{g} \mathrm{m}^{-3}$ versus $1.62 \mu \mathrm{g} \mathrm{m}^{-3}$ in 2013 current and previous models, respectively), the oxygenated functional groups are all substantially higher $\left(1.91 \mu \mathrm{g} \mathrm{m}^{-3}\right.$ versus $0.46 \mu \mathrm{g} \mathrm{m}^{-3}$ respectively). In particular, oxOCO, which was not measured in the previous work, accounted for $\sim 10 \%$ of OM in the current models $\left(0.32 \mu \mathrm{g} \mathrm{m}^{-3}\right)$, adding substantially to the quantified material.

Although there were no rural sites with data from both the 2014 models and the current models, samples from rural sites in the southeastern US region were analyzed using the old and new models (Fig. 4). Similar to the Birmingham site, the predicted $\mathrm{OM}$ concentrations at rural sites were greater when using the current models $\left(2.4 \pm 2.3 \mu \mathrm{g} \mathrm{m}^{-3}\right)$ than the 2014 models $\left(0.74 \pm 0.67 \mu \mathrm{g} \mathrm{m}^{-3}\right)$, again with a larger fraction of OM contributed by oxygenated functional groups using the current model. The increase in $\mathrm{OM}$ and oxygenated functional group concentrations at both urban and rural sites were therefore attributed to the inclusion of a more extensive variety of organic molecules, and in particular to the greater 

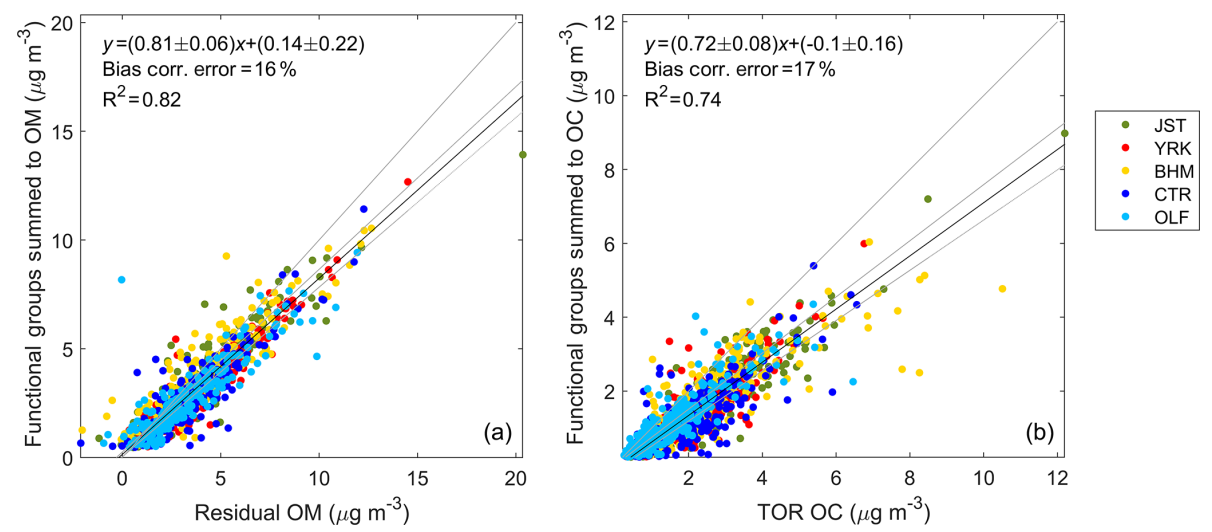

Figure 3. Scatter plots of predicted functional group OM and OC concentrations versus reference measurement concentrations. (a) Reference values are residual OM concentrations; FT-IR OM MDL $=0.38 \mu \mathrm{g} \mathrm{m}^{-3}$. (b) Reference values are TOR OC concentrations; FT-IR OC MDL $=0.19 \mu \mathrm{g} \mathrm{m}^{-3}$. Site abbreviations: JST = Jefferson Street, Atlanta, GA; YRK = Yorkville, GA; BHM = Birmingham, AL; $\mathrm{CTR}=$ Centreville, AL; OLF $=$ an outlying landing field near Pensacola, FL.
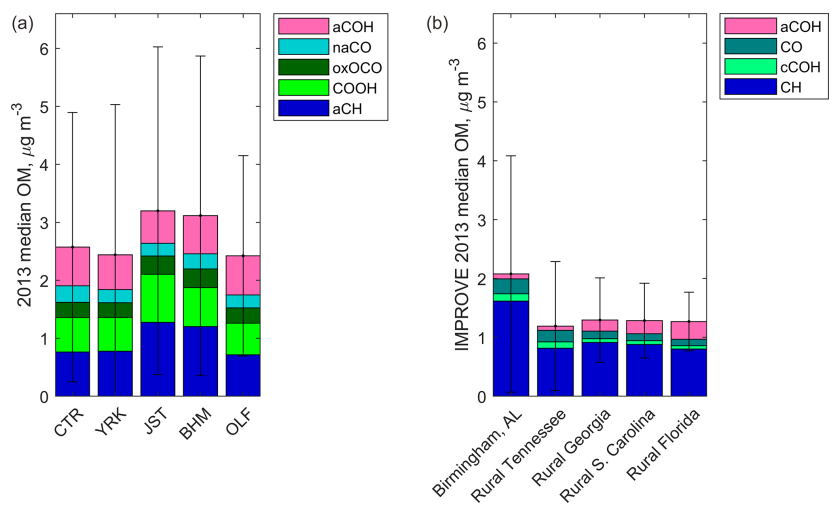

Figure 4. Bar plots of OM median concentrations for all sites, 2013, using the current models and SEARCH ambient samples (left), as compared to previous work (applied by Kamruzzaman et al., 2018, and compared to IMPROVE network samples, using models constructed by Ruthenburg et al., 2014). Error bars represent the interquartile ranges of the total OM concentrations.

variety of oxygenated functional groups in the present models (Fig. 4).

\subsubsection{Evaluating FT-IR measurements: OM/OC ratios}

The ratio of $\mathrm{OM} / \mathrm{OC}$ by mass is a common metric for the degree of oxygenation of an ambient aerosol sample, and it is also used to estimate total OM concentrations from measured TOR OC concentrations (El-Zanan et al., 2009; Simon et al., 2011; Turpin and Lim, 2001). The median OM/OC for all sites and years ( $n=1474$ samples) was $2.1 \pm 0.2$. As shown in Fig. 5, the distributions of OM/OC ratios were slightly different between urban versus rural samples, and between winter (January) versus summer (July) samples. The urban versus rural differences may be muted because of a generally well-mixed atmosphere in the southeastern US (Gao et al.,
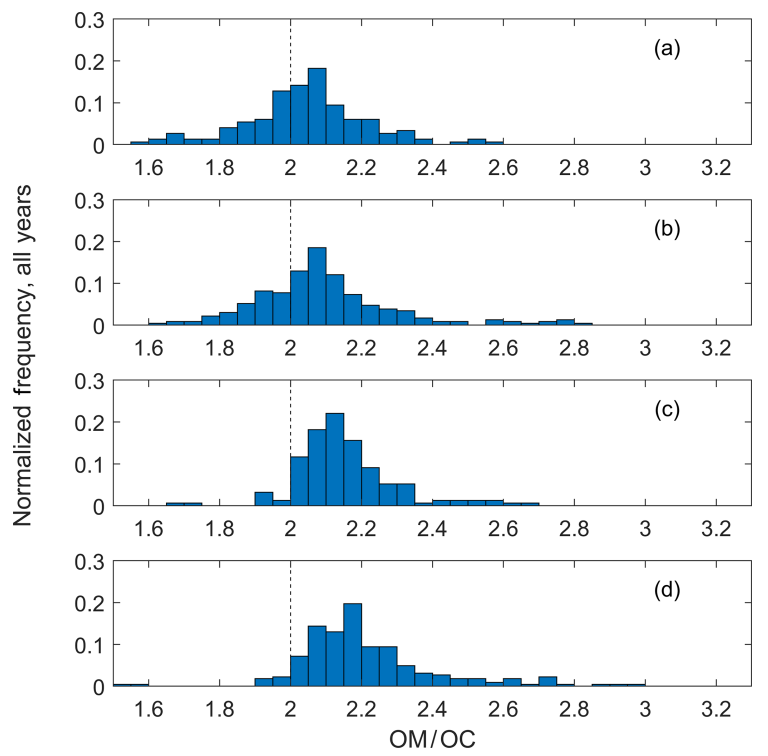

Figure 5. Histograms of OM/OC ratios predicted using functional group measurements, separated into (a) urban (BHM and JST) January, (b) rural (CTR, YRK, and OLF) January, (c) urban July, and (d) rural July. January is used to approximate winter; July is used to approximate summer.

2006; Weber et al., 2007; Xu et al., 2015). Seasonal OM/OC ratio differences in the region are also likely small due to the narrow seasonal temperature variation (Hidy et al., 2014). The greater values at rural sites (Yorkville $2.1 \pm 0.2$ versus Atlanta $2.0 \pm 0.2$ and Centreville $2.1 \pm 0.2$ versus Birmingham $2.0 \pm 0.2$ ) are in agreement with increased secondary organic aerosol contribution to OM downwind of urban emissions sources.

The measured $\mathrm{OM} / \mathrm{OC}$ ratios from the present models are similar to those estimated in another study: El-Zanan et 
al. (2009) measured $\mathrm{OM} / \mathrm{OC}=2 \cdot 16 \pm 0.43$ and $\mathrm{OM} / \mathrm{OC}=$ $2.14 \pm 017$ at JST between July 1998 and December 1999 (mean \pm standard deviation, using gravimetric analysis of solvent extracts and mass balance of organic and total particulate masses, respectively). Multiple linear regression has been applied to IMPROVE data to obtain OM/OC at various locations and times and has resulted in varying values. Simon et al. (2011) found lower median seasonal OM/OC ratios for the southeastern US (between 1.64 and 1.89). An OM/OC of 1.8 , used to calculate reconstructed fine mass concentrations within IMPROVE network samples (Pitchford et al., 2007), is also lower than the median $\mathrm{OM} / \mathrm{OC}$ ratios estimated in this study. However, in more recent work using multiple linear regression, Hand et al. (2019) estimated OM/OC ratios in the southeastern US varying between 1.9 and 2.1 from 2012 to 2016, similar to the ratios presented in this present work. The OM/OC values predicted using previous FT-IR models (Kamruzzaman et al., 2018) were lower than those of the other approaches summarized here and the current FTIR model results: $\mathrm{OM} / \mathrm{OC}=1.4 \pm 0.2$ at urban Birmingham, $\mathrm{AL}$, and $\mathrm{OM} / \mathrm{OC}=1.6 \pm 0.3$ at four rural sites in the southeast (2013 IMPROVE sites). The higher OM/OC ratios in the current work are attributable to the added oxygenated chemicals used to construct the current models and the addition of the oxOCO functional group.

Extremes in measured $\mathrm{OM} / \mathrm{OC}$ ratios were often caused by particularly high or low $\mathrm{C}-\mathrm{H}$ stretching absorption intensity. Spectra of many high OM/OC ratio samples ( $>90$ th percentile of $\mathrm{OM} / \mathrm{OC}$ ) demonstrated low hydrocarbon character; these were mostly rural $(\sim 90 \%)$. Similarly, spectra of low $\mathrm{OM} / \mathrm{OC}$ ratio samples (<10th percentile of OM/OC) demonstrated high hydrocarbon character and were $\sim 90 \%$ urban. Additionally, some extreme values of $\mathrm{OM} / \mathrm{OC}$ were characterized by low OM concentrations, corresponding to functional group concentrations near or below MDLs.

\subsubsection{Evaluating FT-IR measurements: $\mathrm{O} / \mathrm{C}$ and $\mathrm{H} / \mathrm{C}$ ratios}

A van Krevelen diagram was generated using the atomic ratios of $\mathrm{O} / \mathrm{C}$ and $\mathrm{H} / \mathrm{C}$ from the functional groups quantified using FT-IR spectrometry (Fig. 6). The range of mean $\mathrm{O} / \mathrm{C}$ and $\mathrm{H} / \mathrm{C}$ ratios measured by aerosol mass spectrometry in the southeastern US (Xu et al., 2015; summer 2013 data; designated by the black box in Fig. 6), was near the visual mode of the FT-IR predicted values, indicating that the organic composition measured by FT-IR spectrometry is similar to that captured by aerosol mass spectrometry. The similarities are evident despite the fact that there are clearly methodological differences between FT-IR spectrometry and other mass spectrometry techniques used to characterize $\mathrm{O} / \mathrm{C}$ and $\mathrm{H} / \mathrm{C}$ ratios in other aerosol populations (summarized in Chen et al., 2015 and Heald et al., 2010). For example, the composition differs somewhat between $\mathrm{PM}_{2.5}$ (analyzed by FTIR spectrometry in this study) and $\mathrm{PM}_{1}$ (as in aerosol mass

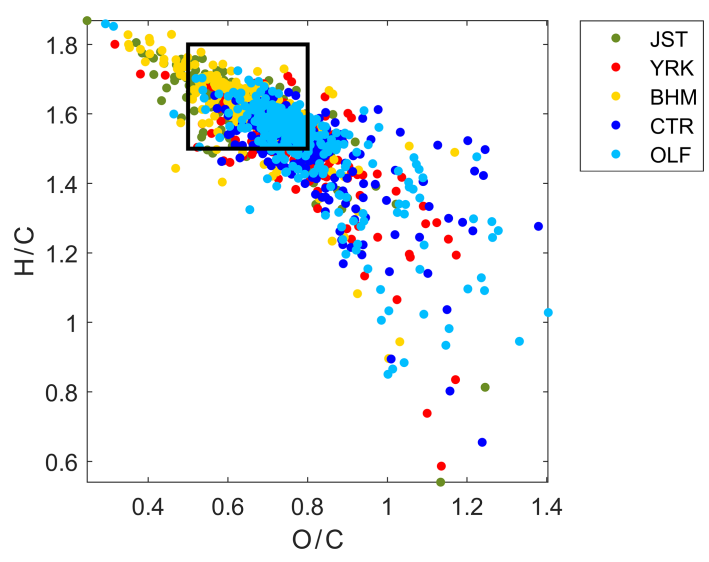

Figure 6. Ratios of $\mathrm{H} / \mathrm{C}$ and $\mathrm{O} / \mathrm{C}$ measured in SEARCH ambient samples using FT-IR spectrometry models, plotted in the van Krevelen space. The bold black box surrounds the data range collected using aerosol mass spectrometry in the southeastern US during the summer of 2013 (Xu et al., 2015).

spectrometry). However, sources are likely similar: Liu et al. (2012) found similar sources of $\mathrm{OM}$ in $\mathrm{PM}_{1}$ and $\mathrm{PM}_{2.5}$ 2012). The agreement between results from the two methods in Fig. 6 demonstrates that the overall chemical composition captured by the FT-IR spectrometry and mass spectrometry techniques is similar.

Aerosol evaluated in this study was less oxidized at the urban sites than the rural sites, as expected: the urban sites had higher $\mathrm{H} / \mathrm{C}$ and lower $\mathrm{O} / \mathrm{C}$ ratios (yellow and green in Fig. 6) than the rural sites. A regional oxidized aerosol character was suggested by the similarity between the van Krevelen spaces occupied by the three rural sites. The spread in $\mathrm{O} / \mathrm{C}$ and $\mathrm{H} / \mathrm{C}$ values in Fig. 6 was reflective of composition and was within the range observed in previous atmospheric aerosol studies (Chen et al., 2015); some scatter was expected over the variety of seasons, sources, and oxidation processes encompassed by this dataset. Extreme data points within the van Krevelen space $(\mathrm{H} / \mathrm{C} \leq 1.2$ and/or $\mathrm{O} / \mathrm{C} \geq 1.2$ ) generally corresponded to spectra with high $\mathrm{Si}$ concentrations (measured in the SEARCH network via Xray fluorescence; see discussion in Sect. S14), low organic feature absorption (below median $\mathrm{C}-\mathrm{H}$ and $\mathrm{C}=\mathrm{O}$ stretching absorption) and/or a low OC concentration (FT-IR spectrometry or TOR). Although high Si concentrations apparently coincided with extreme $\mathrm{O} / \mathrm{C}$ (high) and $\mathrm{H} / \mathrm{C}$ (low) values, these samples were kept in the dataset because there was no other indication of compromised prediction for these samples. Elevated ( $>95$ th percentile) Si concentrations were often observed during summer Saharan dust transport events (Hand et al., 2017), and narrow SiO-H stretching bands are observed in FT-IR spectra between 3600 and $3700 \mathrm{~cm}^{-1}$.

The overall slope of all sites and years of SEARCH samples in the van Krevelen space is -0.72 (orthogonal least squares), which is similar to the slope measured over mul- 
tiple, globally spaced field campaigns using aerosol mass spectrometry $(-0.6 ;-1$ to -0.7 in individual campaigns; Chen et al., 2015). The observed overall slope is intermediate between a van Krevelen space slope of -1 and -0.5 , which could, respectively, approximate replacing a methyl group with a carboxylic acid group (the addition of two $\mathrm{O}$ and removal of two $\mathrm{H}$ atoms), and fragmentation of a $\mathrm{C}-\mathrm{C}$ bond and formation of two carboxylic acid groups ( $\mathrm{Ng}$ et al., 2011). The pattern of the current long-term dataset, which demonstrates atmospheric organic chemical composition integrated over many sources and atmospheric processes, is therefore consistent with common oxidation mechanisms observed in previous studies.

\subsection{Method limitations and future work}

The expansion of the list of chemicals included in the current calibration models from previous work was overall successful relative to the techniques and other study results discussed in the previous sections. These improvements suggest that further expanding and refining the calibration standards may make functional group measurements more accurate, increase the number of functional groups that can be measured, and improve OM recovery. Other chemicals suggested for addition to the models include those used for aerosol mass spectrometry calibration (Aiken et al., 2008; Canagaratna et al., 2015). Additionally, several oxygenated chemicals with multiple functional groups proved difficult to collect in relevant chemical form and quantity for atmospheric aerosol (e.g., tartaric acid; see Sect. S4 and Fig. S4) but should be revisited as atmospherically important species and groups. Other potentially important groups to consider include aldehydes and anhydrides (see Sect. S4). Since it was discovered herein that high silicate (dust) concentrations might degrade the quality of functional group predictions, building calibrations of suspended dust particles could be considered in the future.

Although the extended calibration designed in this work captures variation in the OM speciation beyond that of previous work, there are additional functional groups that should be considered in further work. Kamruzzaman et al. (2018) demonstrated the importance of amine $\mathrm{N}-\mathrm{H}$ and $\mathrm{C}-\mathrm{N}$ bonds in OM calculations, and organosulfate $\mathrm{O}-\mathrm{S}$ and $\mathrm{O}-\mathrm{C}$ bonds are additionally likely to be influential (Stone et al., 2012).

The observed interactions between some polar protic species are acknowledged and should be considered in future work. However, the uncertainties in quantitative multichemical laboratory standards prevented us from including them in the current models. The challenges observed in our explorations have included (1) an inability to measure the weight of each chemical collected from particles generated from a solution with both chemicals and (2) volatilization during sequential collection of chemicals. Multicomponent laboratory standards could be a way to include atmospheric chemical interactions in FT-IR spectrometry models if the above challenges can be overcome or sufficiently minimized.

There are additional sources of uncertainty within the model parameters that should be further addressed. Takahama and Ruggeri (2017) demonstrated that the C/functional group ratio $(\lambda)$ values applied to calculate OM and OC concentrations herein are likely realistic but have some uncertainty and are known to vary for different chemicals. Although the number of standards per chemical, the number of factors in each PLS model, the dynamic range of standards included in each model, and other inputs have been selected carefully, the correct values of these inputs cannot be exactly known. The chemical selection uncertainty addressed in Sect. 3.3.2 cannot entirely capture the variability in model results due to the possible mis-specification of chemicals used in the models and could be further discussed. Despite these challenges, the agreement between our results and many available expected or reference values demonstrates that the results are reasonable (e.g., OM and OC concentrations with previous work, given mass accuracy expectations, realistic trends in urban versus rural concentrations, and the atomic ratios $\mathrm{O} / \mathrm{C}$ and $\mathrm{H} / \mathrm{C}$ ).

\section{Conclusions}

A method of directly estimating $\mathrm{OM}$ concentrations and $\mathrm{OM} / \mathrm{OC}$ ratios with functional group composition has been advanced and evaluated. A multivariate calibration for quantifying five organic functional groups was built using FT-IR spectra and gravimetric weights of chemical standard filters. Spectra and weights of 18 organic chemicals and three interferent chemicals (ammonium sulfate, ammonium nitrate and particle water) were included in the calibration models. Various uncertainties in the method were explored, such as humidity and hydrogen bonding differences between standard spectra. Ambient aerosol composition was quantified from nearly 1500 SEARCH network samples. An estimate of sampling uncertainty was calculated as precision between measurements from colocated sites $\left(0.38 \mu \mathrm{g} \mathrm{m}^{-3}\right.$ or $14 \%$ of $\mathrm{OM})$. The method gave results comparable to more intensive methods or methods that are destructive to the samples, such as OM concentration via summation of various analytical results (residual $\mathrm{OM}$ ), $\mathrm{OC}$ concentration via TOR, $\mathrm{O} / \mathrm{C}$ ratio via aerosol mass spectrometry, and $\mathrm{OM} / \mathrm{OC}$ via filter extraction and chromatography analyses (functional group models accounted for $81 \pm 5 \%$ of residual $\mathrm{OM}, R^{2}=0.82$, and $71 \pm$ $8 \%$ of TOR OC, $R^{2}=0.74$ ). Predictive features in the model excluded inorganic absorption features prominent in atmospheric aerosol FT-IR spectra (for example, bands due to ammonium sulfate and ammonium nitrate). Estimated functional group composition contained predominantly aliphatic $\mathrm{C}-\mathrm{H}$ and carboxylic acid groups, followed by alcohol groups. Oxalates were quantified separately from carboxylic acids and contributed $5 \%-10 \%$ of OM mass $(\sim 40 \%$ as much 
as carboxylic acids). Urban and rural SEARCH site compositions were distinct, with a smaller aliphatic $\mathrm{C}-\mathrm{H}$ fraction, greater oxygenated functional group fraction, and lower OM concentration at rural sites. Further analysis of the SEARCH network data, including trends in OM concentration and composition observed between 2009 and 2016, will be explored in a forthcoming paper.

Data availability. The functional group, OM, and OC concentrations with uncertainties, as well as raw spectra, are available at https://doi.org/10.25338/B8SG73 (Dillner et al, 2019).

Supplement. The supplement related to this article is available online at: https://doi.org/10.5194/amt-12-5391-2019-supplement.

Author contributions. AMD and SLS conceived of the project. AJB performed the laboratory work, developed the calibration models, performed the data analysis, and wrote and edited the paper. ST provided mentoring to AJB on the modeling, data analysis, and writing and editing of the manuscript. ATW, BMD, CB, and MR provided input on the data analysis and modeling and reviewed the paper. CDF and MES provided laboratory and quality control support. ESE provided SEARCH network filters and data and contributed to the manuscript. AMD provided mentoring and supervision of the laboratory, modeling, and data analysis efforts and reviewed and edited the manuscript.

Competing interests. The authors declare that they have no conflict of interest.

Acknowledgements. Funding for this project was generously provided by the Electric Power Research Institute, with equipment and logistical support from Atmospheric Research \& Analysis, Inc. The authors would like to acknowledge the contributions of Kelsey Seibert, who provided extensive lab management and data support for this work. Many undergraduate students were also involved in this project, including Nathaniel Hopper, Matthew Coates, Alex Williams, and Kimberly Bowman.

Financial support. This research has been supported by the Electric Power Research Institute (grant no. 10003745).

Review statement. This paper was edited by Charles Brock and reviewed by Qingcai Chen and one anonymous referee.

\section{References}

Aiken, A. C., Decarlo, P. F., Kroll, J. H., Worsnop, D. R., Huggman, A. J., Docherty, K. S., Ulbrich, I. M., Mohr, C., Kimmel,
J. R., Super, D., Sun, Y., Zhang, Q., Trimborn, A., Northway, M., Ziemann, P. J., Canagaratna, M. R., Onasch, T. B., Alfarra, M. R., Prevot, A. S. H., Dommen, J., Duplissy, J., Metzger, A., Baltensperger, U., Jimenez, J. L., Huffman, J. A., Docherty, K. S., Ulbrich, I. M., Mohr, C., Kimmel, J. R., Super, D., Sun, Y., Zhang, Q., Trimborn, A., Northway, M., Zieman, P. J., Canagaratna, M. R., Onasch, T. B., Alfarra, M. R., Prevot, A. S. H., Dommen, J., Duplissy, J., Metzger, A., Baltensperger, U., and Jimenez, J. L.: O/C and OM/OC Ratios of Primary, Secondary, and Ambient Organic Aerosols with High-Resolution Time-ofFlight Aerosol Mass Spectrometry, Environ. Sci. Technol., 42, 4478-4485, https://doi.org/10.1021/es703009q, 2008.

Allen, D. T., Palen, E. J., Haimov, M. I., Hering, S. V, Young, J. R., Allen, D. T., Palen, E. J., Haimov, M. I., Hering, S. V, Calibration, F., Allen, D. T., Palen, E. J., Mitchell, I., Hering, S. V., and Young, J. R.: Fourier Transform Infrared Spectroscopy of Aerosol Collected in a Low Pressure Impactor (LPI/FTIR): Method Development and Field Calibration, Aerosol Sci. Tech., 21, 325-342, https://doi.org/10.1080/02786829408959719, 1994.

Burki, C., Reggente, M., Dillner, A. M., Hand, J. L., Shaw, S. L., and Takahama, S.: Analysis of functional groups in atmospheric aerosols by infrared spectroscopy: method development for probabilistic modeling of organic carbon and organic matter concentrations, in Preparation, 2019.

Canagaratna, M. R., Jimenez, J. L., Kroll, J. H., Chen, Q., Kessler, S. H., Massoli, P., Hildebrandt Ruiz, L., Fortner, E., Williams, L. R., Wilson, K. R., Surratt, J. D., Donahue, N. M., Jayne, J. T., and Worsnop, D. R.: Elemental ratio measurements of organic compounds using aerosol mass spectrometry: characterization, improved calibration, and implications, Atmos. Chem. Phys., 15, 253-272, https://doi.org/10.5194/acp-15-253-2015, 2015.

Caseiro, A., Marr, I. L., Claeys, M., Kasper-giebl, A., Puxbaum, H., and Pio, C. A.: Determination of saccharides in atmospheric aerosol using anion-exchange high-performance liquid chromatography and pulsed-amperometric detection, J. Chromatogr. A, 1171, 37-45, https://doi.org/10.1016/j.chroma.2007.09.038, 2007.

Chen, Q., Heald, C. L., Jimenez, J. L., Canagaratna, M. R., He, L.Y., Huang, X.-F., Campuzano-Jost, P., Palm, B. B., Poulain, L., Kuwata, M., Martin, S. T., Abbatt, J. P. D., Lee, A. K. Y., and Liggio, J.: Elemental Composition of Organic Aerosol: The Gap Between Ambient and Laboratory Measurements, Geophys. Res. Lett., 42, 1-8, https://doi.org/10.1002/2015GL063693, 2015.

Chen, Q., Ikemori, F., Higo, H., Asakawa, D., and Mochida, M.: Chemical Structural Characteristics of HULIS and Other Fractionated Organic Matter in Urban Aerosols: Results from Mass Spectral and FT-IR Analysis, Environ. Sci. Technol., 50, 17211730, https://doi.org/10.1021/acs.est.5b05277, 2016.

Chong, I. G. and Jun, C. H.: Performance of some variable selection methods when multicollinearity is present, Chemom. Intell. Lab. Syst., 78, 103-112, https://doi.org/10.1016/j.chemolab.2004.12.011, 2005.

Chow, J. C., Watson, J. G., Chen, L. W. A., Arnott, W. P., Moosmüller, H., and Fung, K.: Equivalence of elemental carbon by thermal/optical reflectance and transmittance with different temperature protocols, Environ. Sci. Technol., 38, 4414-4422, https://doi.org/10.1021/es034936u, 2004. 
Chow, J. C., Lowenthal, D. H., Chen, L. W. A., Wang, X., and Watson, J. G.: Mass reconstruction methods for PM2.5: a review, Air Qual. Atmos. Hlth., 8, 243-263, https://doi.org/10.1007/s11869015-0338-3, 2015.

Claeys, M., Graham, B., Vas, G., Wang, W., Vermeylen, R., Pashynska, V., Cafmeyer, J., Guyon, P., Andreae, M. O., Artaxo, P., and Maenhaut, W.: Formation of Secondary Organic Aerosols Through Photooxidation of Isoprene, Science, 303, 1173-1176, https://doi.org/10.1126/science.1092805, 2004.

Coury, C. and Dillner, A. M.: A method to quantify organic functional groups and inorganic compounds in ambient aerosols using attenuated total reflectance FTIR spectroscopy and multivariate chemometric techniques, Atmos. Environ., 42, 5923-5932, https://doi.org/10.1016/j.atmosenv.2008.03.026, 2008.

Coury, C. and Dillner, A. M.: ATR-FTIR characterization of organic functional groups and inorganic ions in ambient aerosols at a rural site, Atmos. Environ., 43, 940-948, https://doi.org/10.1016/j.atmosenv.2008.10.056, 2009.

Cziczo, D. J. and Abbatt, J. P. D.: Infrared Observations of the Response of $\mathrm{NaCl}, \mathrm{MgCl}_{2}, \mathrm{NH}_{4} \mathrm{HSO}_{4}$, and $\mathrm{NH}_{4} \mathrm{NO}_{3}$ Aerosols to Changes in Relative Humidity from 298 to 238 K, J. Phys. Chem. A, 104, 2038-2047, https://doi.org/10.1021/jp9931408, 2000.

Dabek-Zlotorzynska, E., Dann, T. F., Kalyani Martinelango, P., Celo, V., Brook, J. R., Mathieu, D., Ding, L., and Austin, C. C.: Canadian National Air Pollution Surveillance (NAPS) $\mathrm{PM}_{2.5}$ speciation program: Methodology and $\mathrm{PM}_{2.5}$ chemical composition for the years 2003-2008, Atmos. Environ., 45, 673-686, https://doi.org/10.1016/j.atmosenv.2010.10.024, 2011.

Davey, R. J., Dent, G., Mughal, R. K., and Parveen, S.: Concerning the relationship between structural and growth synthons in crystal nucleation: Solution and crystal chemistry of carboxylic acids as revealed through IR spectroscopy, Cryst. Growth Des., 6, 1788-1796, https://doi.org/10.1021/cg060058a, 2006.

Debus, B., Takahama, S., Weakley, A. T., Seibert, K., and Dillner, A. M.: Long-Term Strategy for Assessing Carbonaceous Particulate Matter Concentrations from Multiple Fourier Transform Infrared (FT-IR) Instruments: Influence of Spectral Dissimilarities on Multivariate Calibration Performance, Appl. Spectrosc., 73, 271-283, https://doi.org/10.1177/0003702818804574, 2019.

Decesari, S., Mircea, M., Cavalli, F., Fuzzi, S., Moretti, F., Tagliavini, E., and Facchini, M. C.: Source Attribution of Water-Soluble Organic Aerosol by Nuclear Magnetic Resonance Spectroscopy, Environ. Sci. Technol., 41, 2479-2484, https://doi.org/10.1021/es0617111, 2007.

Dillner, A. M., Boris, A. J., Takahama, S., Weakley, A. T., Debus, B., Frederickson, C. D., Esparza-Sanchez, M., Burke, C., Reggente, M., Shaw, S. L., and Edgerton, E. S.: Organic functional group and organic matter concentrations from FT-IR measurements of particulate matter samples in the Southeastern Aerosol Research and Characterization (SEARCH) network from 2009-2016, UC Davis, Dataset, https://doi.org/10.25338/B8SG73, 2019.

Edgerton, E. S., Hartsell, B. E., Saylor, R. D., Jansen, J. J., Hansen, D. A., and Hidy, G. M.: The Southeastern Aerosol Research and Characterization Study, part II: Filterbased measurements of fine and coarse particulate matter mass and composition, J. Air Waste Manage., 55, 1527-1542, https://doi.org/10.1080/10473289.2005.10464744, 2005.
El-Zanan, H. S., Zielinska, B., Mazzoleni, L. R., and Hansen, D. A.: Analytical determination of the aerosol organic massto-organic carbon ratio, J. Air Waste Manage., 59, 58-69, https://doi.org/10.3155/1047-3289.59.1.58, 2009.

Faber, P., Drewnick, F., Bierl, R., and Borrmann, S.: Complementary online aerosol mass spectrometry and offline FT-IR spectroscopy measurements: Prospects and challenges for the analysis of anthropogenic aerosol particle emissions, Atmos. Environ., 166, 92-98, https://doi.org/10.1016/j.atmosenv.2017.07.014, 2017.

Frossard, A. A. and Russell, L. M.: Removal of sea salt hydrate water from seawater-derived samples by dehydration, Environ. Sci. Technol., 46, 13326-13333, https://doi.org/10.1021/es3032083, 2012.

Gao, S., Surratt, J. D., Knipping, E. M., Edgerton, E. S., Shahgholi, M., and Seinfeld, J. H.: Characterization of polar organic components in fine aerosols in the southeastern United States: Identity, origin, and evolution, J. Geophys. Res., 111, D14314, https://doi.org/10.1029/2005JD006601, 2006.

George, K. M., Ruthenburg, T. C., Smith, J., Yu, L., Zhang, Q., Anastasio, C., and Dillner, A. M.: FT-IR quantification of the carbonyl functional group in aqueous-phase secondary organic aerosol from phenols, Atmos. Environ., 100, 230-237, https://doi.org/10.1016/j.atmosenv.2014.11.011, 2015.

Guo, H., Xu, L., Bougiatioti, A., Cerully, K. M., Capps, S. L., Hite Jr., J. R., Carlton, A. G., Lee, S.-H., Bergin, M. H., Ng, N. L., Nenes, A., and Weber, R. J.: Fine-particle water and $\mathrm{pH}$ in the southeastern United States, Atmos. Chem. Phys., 15, 5211-5228, https://doi.org/10.5194/acp-15-5211-2015, 2015.

Haagen-Smit, A. J.: Chemistry and Physiology of Los Angeles Smog, Ind. Eng. Chem., 44, 1342-1346, https://doi.org/10.1021/ie50510a045, 1952.

Hallar, A. G., Lowenthal, D. H., Clegg, S. L., Samburova, V., Taylor, N., Mazzoleni, L. R., Zielinska, B. K., Kristensen, T. B., Chirokova, G., McCubbin, I. B., Dodson, C., and Collins, D.: Chemical and hygroscopic properties of aerosol organics at Storm Peak Laboratory, J. Geophys. Res.-Atmos., 118, 4767 4779, https://doi.org/10.1002/jgrd.50373, 2013.

Hamilton, J. F., Webb, P. J., Lewis, A. C., Hopkins, J. R., Smith, S., and Davy, P.: Partially oxidised organic components in urban aerosol using GCXGC-TOF/MS, Atmos. Chem. Phys., 4, 12791290, https://doi.org/10.5194/acp-4-1279-2004, 2004.

Hand, J. L., Schichtel, B. A., Pitchford, M., Malm, W. C., and Frank, N. H.: Seasonal composition of remote and urban fine particulate matter in the United States, J. Geophys. Res.-Atmos., 117, 1-22, https://doi.org/10.1029/2011JD017122, 2012.

Hand, J. L., Gill, T. E., and Schichtel, B. A.: Spatial and seasonal variability in fine mineral dust and coarse aerosol mass at remote sites across the United States, J. Geophys. Res., 122, 3080-3097, https://doi.org/10.1002/2016JD026290, 2017.

Hand, J. L., Prenni, A. J., Schichtel, B. A., Malm, W. C., and Chow, J. C.: Trends in remote $\mathrm{PM}_{2.5}$ residual mass across the United States: Implications for aerosol mass reconstruction in the IMPROVE network, Atmos. Environ., 203, 141-152, https://doi.org/10.1016/j.atmosenv.2019.01.049, 2019.

Hansen, D. A., Edgerton, E. S., Hartsell, B. E., Jansen, J. J., Kandasamy, N., Hidy, G. M., Blanchard, C. L., Hansen, D. A., Edgerton, E. S., Hartsell, B. E., Jansen, J. J., Kandasamy, N., Hidy, G. M., The, C. L. B., Hansen, D. A., Edgerton, E. S., Hartsell, B. 
E., Jansen, J. J., Kandasamy, N., Hidy, G. M., and Blanchard, C. L.: The Southeastern Aerosol Research and Characterization Study?: Part 1 - Overview, J. Air Waste Manage., 53, 1460-1471, https://doi.org/10.1080/10473289.2003.10466318, 2003.

Harrison, M., Barra, S., Borghesi, D., Vione, D., Arsene, C., and Iulianolariu, R.: Nitrated phenols in the atmosphere: a review, Atmos. Environ., 39, 231-248, doi:10.1016/j.atmosenv.2004.09.044, 2005.

Heald, C. L., Kroll, J. H., Jimenez, J. L., Docherty, K. S., DeCarlo, P. F., Aiken, A. C., Chen, Q., Martin, S. T., and Farmer, D. K.: A simplified description of the evolution of organic aerosol composition in the atmosphere, Geophys. Res. Lett., 37, L08803, https://doi.org/10.1029/2010GL042737, 2010.

Helsel, D. R.: More Than Obvious: Better Methods for Interpreting Nondetect Data, Environ. Sci. Technol., 39, 419A-423A, https://doi.org/10.1021/es053368a, 2005.

Hettiyadura, A. P. S., Stone, E. A., Kundu, S., Baker, Z., Geddes, E., Richards, K., and Humphry, T.: Determination of atmospheric organosulfates using HILIC chromatography with MS detection, Atmos. Meas. Tech., 8, 2347-2358, https://doi.org/10.5194/amt8-2347-2015, 2015.

Hidy, G. M., Blanchard, C. L., Baumann, K., Edgerton, E., Tanenbaum, S., Shaw, S., Knipping, E., Tombach, I., Jansen, J., and Walters, J.: Chemical climatology of the southeastern United States, 1999-2013, Atmos. Chem. Phys., 14, 11893-11914, https://doi.org/10.5194/acp-14-11893-2014, 2014.

Hoaglin, D. C. and Welsch, R. E.: The Hat Matrix in Regression and ANOVA, Am. Stat., 32, 17-22, https://doi.org/10.1080/00031305.1978.10479237, 1978.

Hyslop, N. P. and White, W. H.: An evaluation of interagency monitoring of protected visual environments (IMPROVE) collocated precision and uncertainty estimates, Atmos. Environ., 42, 26912705, https://doi.org/10.1016/j.atmosenv.2007.06.053, 2008.

Hyslop, N. P. and White, W. H.: Estimating precision using duplicate measurements, J. Air Waste Manage., 59, 1032-1039, https://doi.org/10.3155/1047-3289.59.9.1032, 2009.

Kahnt, A., Vermeylen, R., Iinuma, Y., Safi Shalamzari, M., Maenhaut, W., and Claeys, M.: High-molecular-weight esters in $\alpha$ pinene ozonolysis secondary organic aerosol: structural characterization and mechanistic proposal for their formation from highly oxygenated molecules, Atmos. Chem. Phys., 18, 84538467, https://doi.org/10.5194/acp-18-8453-2018, 2018.

Kamruzzaman, M., Takahama, S., and Dillner, A. M.: Quantification of amine functional groups and their influence on OM/OC in the IMPROVE network, Atmos. Environ., 172, 124-132, https://doi.org/10.1016/j.atmosenv.2017.10.053, 2018.

Kawamura, K. and Bikkina, S.: A review of dicarboxylic acids and related compounds in atmospheric aerosols: Molecular distributions, sources and transformation, Atmos. Res., 170, 140-160, https://doi.org/10.1016/j.atmosres.2015.11.018, 2016.

Kuzmiakova, A., Dillner, A. M., and Takahama, S.: An automated baseline correction protocol for infrared spectra of atmospheric aerosols collected on polytetrafluoroethylene (Teflon) filters, Atmos. Meas. Tech., 9, 2615-2631, https://doi.org/10.5194/amt-92615-2016, 2016.

Ledesma, S., Ruiz, J., and Garcia, G.: Simulated Annealing Evolution, in: Simulated Annealing: Advances, Applications and Hybridizations, edited by: Tsuzuki, M. S. G., InTech, 2012.
Liu, J., Russell, L. M., Ruggeri, G., Takahama, S., Claflin, M. S., Ziemann, P. J., Pye, H. O. T., Murphy, B. N., Xu, L., Ng, N. L., McKinney, K. A., Budisulistiorini, S. H., Bertram, T. H., Nenes, A., and Surratt, J. D.: Regional Similarities and NOx-Related Increases in Biogenic Secondary Organic Aerosol in Summertime Southeastern United States, J. Geophys. Res.-Atmos., 123 , 10620-10636, https://doi.org/10.1029/2018JD028491, 2018.

Liu, S., Takahama, S., Russell, L. M., Gilardoni, S., and Baumgardner, D.: Oxygenated organic functional groups and their sources in single and submicron organic particles in MILAGRO 2006 campaign, Atmos. Chem. Phys., 9, 6849-6863, https://doi.org/10.5194/acp-9-6849-2009, 2009.

Liu, S., Ahlm, L., Day, D. A., Russell, L. M., Zhao, Y., Gentner, D. R., Weber, R. J., Goldstein, A. H., Jaoui, M., Offenberg, J. H., Kleindienst, T. E., Rubitschun, C., Surratt, J. D., Sheesley, R. J., and Scheller, S.: Secondary organic aerosol formation from fossil fuel sources contribute majority of summertime organic mass at Bakersfield, J. Geophys. Res.-Atmos., 117, 1-21, https://doi.org/10.1029/2012JD018170, 2012.

Malm, W. C. and Hand, J. L.: An examination of the physical and optical properties of aerosols collected in the IMPROVE program, Atmos. Environ., 41, 3407-3427, https://doi.org/10.1016/j.atmosenv.2006.12.012, 2007.

Maroń, M. K., Takahashi, K., Shoemaker, R. K., and Vaida, V.: Hydration of pyruvic acid to its geminaldiol, 2,2-dihydroxypropanoic acid, in a water-restricted environment, Chem. Phys. Lett., 513, 184-190, https://doi.org/10.1016/j.cplett.2011.07.090, 2011.

Mayo, D. W., Miller, F. A., and Robert W, H.: Course Notes on the Interpretation of Infrared and Raman Spectra, John Wiley \& Sons, Inc., Hoboken, New Jersey, 2003.

Mayol-Bracero, O. L., Guyon, P., Graham, B., Roberts, F., Andreae, M. O., Decesari, S., Facchini, M. C., Fuzzi, S., and Artaxo, P. Water-soluble organic compounds in biomass burning aerosols over Amazonia 2. Apportionment of the chemical composition and importance of the polyacidic fraction, J. Geophys. Res., 107, 8091, https://doi.org/10.1029/2001JD000522, 2002.

Mikhailov, E., Vlasenko, S., Martin, S. T., Koop, T., and Pöschl, U.: Amorphous and crystalline aerosol particles interacting with water vapor: conceptual framework and experimental evidence for restructuring, phase transitions and kinetic limitations, Atmos. Chem. Phys., 9, 9491-9522, https://doi.org/10.5194/acp-9-94912009, 2009.

Moretti, F., Tagliavini, E., Decesari, S., Facchini, M. C., Rinaldi, M., and Fuzzi, S.: NMR determination of total carbonyls and carboxyls: A tool for tracing the evolution of atmospheric oxidized organic aerosols, Environ. Sci. Technol., 42, 4844-4849, https://doi.org/10.1021/es703166v, 2008.

Naes, T., Isaksson, T., Fearn, T., and Davies, T.: A User-Friendly Guide to Multivariate Calibration and Classification, NIR Publications, Chichester, 2002.

National Institute of Advanced Industrial Science and Technology: SDBSWeb, available at: https://sdbs.db.aist.go.jp (last access: 9 December 2019), 2018.

Ng, N. L., Canagaratna, M. R., Jimenez, J. L., Chhabra, P. S., Seinfeld, J. H., and Worsnop, D. R.: Changes in organic aerosol composition with aging inferred from aerosol mass spectra, Atmos. Chem. Phys., 11, 6465-6474, https://doi.org/10.5194/acp11-6465-2011, 2011. 
Pavia, D. L., Lampman, G. M., Kriz, G. S., and Vyvyan, J. R.: Introduction to Spectroscopy, Fourth, Brooks/Cole Cengage Learning, Belmont, CA, 2009.

Pitchford, M., Malm, W., Schichtel, B., Kumar, N., Lowenthal, D., and Hand, J.: Revised algorithm for estimating light extinction from IMPROVE particle speciation data, J. Air Waste Manage., 57, 1326-1336, https://doi.org/10.3155/1047-3289.57.11.1326, 2007.

Polidori, A., Turpin, B. J., Davidson, C. I., Rodenburg, L. A., and Maimone, F.: Organic $\mathrm{PM}_{2.5}$ : Fractionation by Polarity, FTIR Spectroscopy, and OM/OC Ratio for the Pittsburgh Aerosol, Aerosol Sci. Tech., 42, 233-246, https://doi.org/10.1080/02786820801958767, 2008.

Polissar, A. V, Hopke, P. K., Paatero, P., Malm, W. C., and Sisler, J. F.: Atmospheric aerosol over Alaska. II. Elemental composition and sources, J. Geophys. Res., 103, 19045-19057, 1998.

Reff, A., Turpin, B. J., Porcja, R. J., Giovennetti, R., Cui, W., Weisel, C. P., Zhang, J., Kwon, J., Alimokhtari, S., Morandi, M., Stock, T., Maberti, S., Colome, S., Winer, A., Shendell, D., Jones, J., and Farrar, C.: Functional group characterization of indoor, outdoor, and personal $\mathrm{PM}_{2.5}$ : Results from RIOPA, Indoor Air, 15, 53-61, https://doi.org/10.1111/j.16000668.2004.00323.x, 2005.

Reff, A., Turpin, B. J., Offenberg, J. H., Weisel, C. P., Zhang, J., Morandi, M., Stock, T., Colome, S., and Winer, A.: A functional group characterization of organic PM2.5 exposure: Results from the RIOPA study, Atmos. Environ., 41, 4585-4598, https://doi.org/10.1016/j.atmosenv.2007.03.054, 2007.

Reggente, M., Dillner, A. M., and Takahama, S.: Analysis of functional groups in atmospheric aerosols by infrared spectroscopy: systematic intercomparison of calibration methods for US measurement network samples, Atmos. Meas. Tech., 12, 2287-2312, https://doi.org/10.5194/amt-12-2287-2019, 2019.

Rogge, W. and Hildemann, L.: Sources of fine organic aerosol. 6. Cigarette smoke in the urban atmosphere, Environ. Sci. Technol., 28, 1375-1388, https://doi.org/10.1021/es00056a030, 1994.

Rogge, W. F., Mazurek, M. A., Hildemann, L. M., Cass, G. R., and Simoneit, B. R. T.: Quantification of urban organic aerosols at a molecular level: Identification, abundance and seasonal variation, Atmos. Environ. A-Gen., 27, 1309-1330, https://doi.org/10.1016/0960-1686(93)90257-Y, 1993.

Russell, L. M.: Aerosol Organic-Mass-to-Organic-Carbon Ratio Measurements, Environ. Sci. Technol., 37, 2982-2987, 2003.

Russell, L. M., Bahadur, R., Hawkins, L. N., Allan, J., Baumgardner, D., Quinn, P. K., and Bates, T. S.: Organic aerosol characterization by complementary measurements of chemical bonds and molecular fragments, Atmos. Environ., 43, 61006105, https://doi.org/10.1016/j.atmosenv.2009.09.036, 2009a.

Russell, L. M., Takahama, S., Liu, S., Hawkins, L. N., Covert, D. S., Quinn, P. K., and Bates, T. S.: Oxygenated fraction and mass of organic aerosol from direct emission and atmospheric processing measured on the R/V Ronald Brown during TEXAQS/GoMACCS 2006, J. Geophys. Res.-Atmos., 114, 1-15, https://doi.org/10.1029/2008JD011275, 2009b.

Russell, L. M., Bahadur, R., and Ziemann, P. J.: Identifying organic aerosol sources by comparing functional group composition in chamber and atmospheric particles, P. Natl. Acad. Sci. USA, 108, 3516-3521, https://doi.org/10.1073/pnas.1006461108, 2011.
Ruthenburg, T. C., Perlin, P. C., Liu, V., McDade, C. E., and Dillner, A. M.: Determination of organic matter and organic matter to organic carbon ratios by infrared spectroscopy with application to selected sites in the IMPROVE network, Atmos. Environ., 86, 47-57, https://doi.org/10.1016/j.atmosenv.2013.12.034, 2014.

Schum, S. K., Zhang, B., Džepina, K., Fialho, P., Mazzoleni, C., and Mazzoleni, L. R.: Molecular and physical characteristics of aerosol at a remote free troposphere site: implications for atmospheric aging, Atmos. Chem. Phys., 18, 14017-14036, https://doi.org/10.5194/acp-18-14017-2018, 2018.

Simon, H., Bhave, P. V., Swall, J. L., Frank, N. H., and Malm, W. C.: Determining the spatial and seasonal variability in OM/OC ratios across the US using multiple regression, Atmos. Chem. Phys., 11, 2933-2949, https://doi.org/10.5194/acp11-2933-2011, 2011.

Stone, E. A., Yang, L., Yu, L. E., and Rupakheti, M.: Characterization of organosulfates in atmospheric aerosols at Four Asian locations, Atmos. Environ., 47, 323-329, https://doi.org/10.1016/j.atmosenv.2011.10.058, 2012.

Sun, Y., Zhang, Q., Zheng, M., Ding, X., Edgerton, E. S., and Wang, $\mathrm{X}$.: Characterization and source apportionment of water-soluble organic matter in atmospheric fine particles $\left(\mathrm{PM}_{2.5}\right)$ with highresolution aerosol mass spectrometry and GC-MS., Environ. Sci. Technol., 45, 4854-4861, https://doi.org/10.1021/es200162h, 2011.

Takahama, S. and Ruggeri, G.: Technical note: Relating functional group measurements to carbon types for improved modelmeasurement comparisons of organic aerosol composition, Atmos. Chem. Phys., 17, 4433-4450, https://doi.org/10.5194/acp17-4433-2017, 2017.

Takahama, S., Johnson, A., and Russell, L. M.: Quantification of Carboxylic and Carbonyl Functional Groups in Organic Aerosol Infrared Absorbance Spectra, Aerosol Sci. Tech., 47, 310-325, https://doi.org/10.1080/02786826.2012.752065, 2013.

Turpin, B. J. and Lim, H.-J.: Species Contributions to PM2.5 Mass Concentrations: Revisiting Common Assumptions for Estimating Organic Mass, Aerosol Sci. Tech., 35, 602-610, https://doi.org/10.1080/02786820152051454, 2001.

U.S. Environmental Protection Agency: Appendix L to Part 50Reference Method for the Determination of Fine Particulate Matter as $\mathrm{PM}_{2.5}$ in the Atmosphere, available at: https://gov.ecfr.io/ cgi-bin/ECFR (last access: 9 December 2019), 2011.

Wang, G., Kawamura, K., Cheng, C., Li, J., Cao, J., Zhang, R., Zhang, T., Liu, S., and Zhao, Z.: Molecular distribution and stable carbon isotopic composition of dicarboxylic acids, ketocarboxylic acids, and $\alpha$-dicarbonyls in size-resolved atmospheric particles from Xi'an City, China, Environ. Sci. Technol., 46, 4783-4791, https://doi.org/10.1021/es204322c, 2012.

Weakley, A. T., Takahama, S., and Dillner, A. M.: Ambient aerosol composition by infrared spectroscopy and partial least-squares in the chemical speciation network: Organic carbon with functional group identification, Aerosol Sci. Tech., 50, 1096-1114, https://doi.org/10.1080/02786826.2016.1217389, 2016.

Weber, R. J., Sullivan, A. P., Peltier, R. E., Russell, A., Yan, B., Zheng, M., de Gouw, J., Warneke, C., Brock, C., Holloway, J. S., Atlas, E. L., and Edgerton, E.: A study of secondary organic aerosol formation in the anthropogenic-influenced southeastern United States, J. Geophys. Res.-Atmos., 112, D13302, https://doi.org/10.1029/2007JD008408, 2007. 
Weis, D. D. and Ewing, G. E.: Infrared spectroscopic signatures of $\left(\mathrm{NH}_{4}\right)_{2} \mathrm{SO}_{4}$ aerosols, J. Geophys. Res.-Atmos., 101, 1870918720, https://doi.org/10.1029/96JD01543, 1996.

Went, F.: Blue Hazes in the Atmosphere, Nature, 4738, 641-643, https://doi.org/10.1038/187641a0, 1960.

White, W. H., Roberts, P. T., and Laboratories, W. M. K.: On the Nature and Origins of Visibility-Reducing Aerosols in the Los Angeles Air Basin, Atmos. Environ., 11, 803-812, https://doi.org/10.1016/0004-6981(77)90042-7, 1977.

Wold, S. and Sjostrom, M.: PLS-regression: A basic tool of chemometrics, Chemom. Intell. Lab. Syst., 58, 109-130, 2001.

Xu, L., Suresh, S., Guo, H., Weber, R. J., and Ng, N. L.: Aerosol characterization over the southeastern United States using high-resolution aerosol mass spectrometry: spatial and seasonal variation of aerosol composition and sources with a focus on organic nitrates, Atmos. Chem. Phys., 15, 7307-7336, https://doi.org/10.5194/acp-15-7307-2015, 2015.
Yang, L. and Yu, L. E.: Measurements of oxalic acid, oxalates, malonic acid, and malonates in atmospheric particulates, Environ. Sci. Technol., 42, 9268-9275, https://doi.org/10.1021/es801820z, 2008.

Yu, X. Y., Lee, T., Ayres, B., Kreidenweis, S. M., Malm, W., and Collett, J. L.: Loss of fine particle ammonium from denuded nylon filters, Atmos. Environ., 40, 4797-4807, https://doi.org/10.1016/j.atmosenv.2006.03.061, 2006. 